\title{
Die Beziehungen zwischen Württemberg und dem Deutschen Orden in der Regierungszeit Graf Eberhards III. von Württemberg (1392-1417)
}

\author{
Von Christoph Florian
}

Der württembergische Graf Eberhard III. wird vor allem als politischer Akteur im Südwesten des Reiches wahrgenommen ${ }^{1}$. Mit der Herrschaft Württemberg als solider Machbasis knüpfte und pflegte er Beziehungen zu zahlreichen territorialen Akteuren im südwestdeutschen Raum. Er schloss unter anderem Bündnisse mit Österreich und Bayern². Vor allem die Verbindung mit den schwäbischen Reichsstädten jedoch, mit denen er über 20 Jahre lang von 1395 bis zum Ende seiner Regierung ununterbrochen verbündet war, und welche das „stabilste Element der Friedensordnung in Schwaben "3 darstellte, steigerten sein Ansehen und seine politische Macht ${ }^{4}$.

Mit dem Erwerb der Herrschaft Mömpelgard (1397) griff er dann über seinen bisherigen politischen Aktionsraum hinaus, kam mit der burgundischen Machtsphäre in Kontakt und musste Burgund in sein politisches Kalkül miteinbeziehen ${ }^{5}$. Bündnisse mit der Stadt Straßburg (1399) ${ }^{6}$ und dem Hochstift Straßburg (13971399) ${ }^{7}$ dokumentieren die neuen Interessen im Westen und verdeutlichen die Bestrebungen, die neue Erwerbung auch bündnispolitisch abzusichern. Jedoch hatte es schon zuvor noch eine andere - beträchtliche - Erweiterung des politi-

1 Vgl. Dieter Mertens, Württemberg, in: Handbuch der baden-württembergischen Geschichte, hg. von Meinrad SchaAb/Hansmartin Schwarzmaier, Bd.2, Stuttgart 1995, S.1-163, hier: S.44f.; Christoph Florian: Graf Eberhard der Milde von Württemberg (1392-1417). Frieden und Bündnisse als Mittel der Politik (Tübinger Bausteine zur Landesgeschichte 6), Ostfildern 2006. - Die angegebenen Daten zu Regierungszeiten und Lebensdauer nach Lexikon des Mittelalters. Studienausgabe, Bd.1-9, Stuttgart/Weimar 1999 (künftig: LexMA).

${ }^{2}$ Mit Österreich (1394-1397, 1400-1402, 1407-1417), mit Bayern (1398), wobei die Dauer letzterer Verbindung nicht bekannt ist, Florian (wie Anm.1) S. 124 f., 168.

3 Mertens (wie Anm.1) S. 45.

${ }^{4}$ Florian (wie Anm.1) bes. S. 1 f., 41.

5 Ebd., S. 120.

${ }^{6}$ Die Dauer ist nicht bekannt, Florian (wie Anm. 1) S. 114.

7 Florian (wie Anm. 1) S. $107 \mathrm{f}$. 
schen Aktionsraums gegeben. Es handelt sich dabei um die Verbindungen zur Deutschordensherrschaft in Preußen ${ }^{8}$. Im Jahr 1393 hatte Eberhard dorthin eine spektakuläre Reise (fortan Preußenreise genannt) unternommen. Von diesem Zeitpunkt an bis in die Regierungszeit seines Sohnes Eberhard IV. (1417-1419) lassen sich dann Kontakte zwischen der Ordensherrschaft und Württemberg erkennen.

Die Preußenreise Eberhards im Jahr 1393 erweckte seit dem 19. Jahrhundert das verstärkte Interesse von Historikern'. Die Episode wurde dabei als eine Art Abenteuer betrachtet, das keinerlei Auswirkungen auf die württembergische Territorialpolitik hatte. So schrieb Christoph Friedrich von Stälin 1856: „Ritterlicher Unternehmungsgeist trieb den Grafen Eberhard von Wirtemberg im J. 1393 [...] nach Preußen zur Heidenfahrt"10. Weitere Überlieferungen aus den Quellen über die Beziehungen Eberhards zum Deutschen Ordensstaat wurden Anfang des 20. Jahrhunderts zur Kenntnis genommen ${ }^{11}$, doch eine Interpretation der Ereignisse sowie deren Einfügung in das Gesamtbild von Eberhards Politik fanden nicht statt.

Die Beziehungen Eberhards zur Deutschordensherrschaft in Preußen sollen daher in dem vorliegenden Aufsatz beschrieben und untersucht werden. Zunächst wird versucht, die Preußenreise aus den wenigen vorhandenen Quellen zu rekonstruieren. Dann werden die nach 1393 nachweisbaren Beziehungen zwischen dem Grafen und dem Orden skizziert. An diese beiden Darstellungen knüpft sich anschließend die Frage nach den Gründen Eberhards für diese Politik. Dazu gehört schließlich auch die Überlegung, wie sich die Beziehungen des Grafen zum Deutschen Orden auf die Herrschaft Württemberg bzw. seine Dynastie ausgewirkt haben. Am Ende sollen die Beziehungen im Gesamtgefüge der herrschaftlichen Politik Eberhards verortet werden.

Der zeitliche Rahmen wird zum einen durch die Preußenreise 1393 und zum anderen durch das Ende der Regierungszeit Eberhards bzw. dessen gleichnamigen Sohnes gebildet. Danach änderten sich die politischen Voraussetzungen, als in Württemberg ab 1419 eine Vormundschaftsregierung eingesetzt wurde, und auch in den Quellen finden sich keine Nachweise mehr.

${ }^{8}$ Mit Quellen- und Literaturverweisen zu den württembergisch-preußischen Beziehungen Florian (wie Anm.1) S.16f., 88 f.; Barbara Hammes, Fürst und Ritterschaft. Konkurrierende Vergegenwärtigung ritterlich-höfischer Tradition im Umkreis südwestdeutscher Fürstenhöfe 1350-1450 (VKgL B 185), Stuttgart 2011, S. 57, 79.

9 Vgl. Florian (wie Anm.1) S.16f., $88 \mathrm{f}$.

10 Christoph Friedrich von STÄLIN, Wirtembergische Geschichte, 3. Teil, Stuttgart 1856, ND [1980], S. 358.

11 Theodor SchöN, Beziehungen Württembergs zum deutschen Orden in Preußen, in: Diözesan-Archiv von Schwaben 20 (1902) S. 161-165, 179-181; 21 (1903) S. 14-16, 45-48, hier S. 47 f., $49-53,84-88$, hier S. 85 ff., $104-109$, 153-158, hier S. 153 u. 155, 171-178; 22 (1904) S.38-43, 65-72, 126-128, 134-141, 155-160, 155-160, 177-183; 23 (1905) S. $36-43,81-88,123-127,150-157$. 


\section{Die Überlieferung}

$\mathrm{Zu}$ den Beziehungen zwischen Graf Eberhard und dem Deutschen Orden gibt es nur eine geringe Quellenüberlieferung, über die im Folgenden ein Überblick gegeben werden soll. Insbesondere zur Rekonstruktion der Preußenreise Eberhards muss daher öfter auf Analogieschlüsse zurückgegriffen werden.

Die ungedruckten Quellen zum Forschungsthema liegen hauptsächlich im Geheimen Staatsarchiv Preußischer Kulturbesitz in Berlin in den Beständen Ordensbriefarchiv (OBA) und Ordensfolianten (OF), im Hauptstaatsarchiv Stuttgart finden sich nur einige wenige Belege. Die nichtpublizierten Quellen beziehen sich mit einer Ausnahme nur auf die württembergisch-preußischen Beziehungen nach 1393. Was die gedruckten Quellen betrifft, so sind hier an erster Stelle das Tresslerbuch $^{12}$ (1399-1409), das Amtsbuch des Tresslers (oberster Finanzverwalter) des Deutschen Ordens, und die jüngst erschienenen „Regesten zu den Briefregistern des Deutschen Ordens"13 zu nennen.

Über die Preußenreise Eberhards geben fast ausschließlich historiographische Quellen Auskunft. Erstmals wurde das Ereignis durch die Herausgabe der Chronik Johann von Posilges durch Johannes Voigt und Friedrich Wilhelm Schubert 1823 einem breiteren interessierten Publikum außerhalb Württembergs bekannt gemacht ${ }^{14}$. Die über die Preußenfahrt Eberhards berichtenden spätmittelalterlichen preußischen historiographischen und chronikalischen Werke wurden dann, soweit bekannt, in den „Scriptores rerum Prussicarum“15 ediert. Am ausführlichsten geht dort die Chronik Wigands von Marburg auf die Geschehnisse ein ${ }^{16}$. Weitere in diesem Quellenkorpus veröffentlichte Werke, die über die Geschehnisse berichten, sind die dort nochmals edierte Chronik Johann von Posilges ${ }^{17}$, die

12 Das Marienburger Tresslerbuch der Jahre 1399-1409, hg. von [Erich] JoAchim, Königsberg 1896 (künftig: TB), S. 37, 77, 114, 124, 156, 192, 194, 252, 272, 300, 323, 356, $361 \mathrm{f} ., 448,506,594$.

13 Regesten zu den Briefregistern des Deutschen Ordens II: Die Ordensfolianten 8, 9 und Zusatzmaterial, hg. u. bearb. von Sebastian Kubon/Jürgen SARnowsky/Annika Sounr-Könighaus (Beihefte zum Preußischen Urkundenbuch 2), Göttingen 2014, S. 107 Nr. 56, S. 107, Nr. 99, S. 131, Nr.266, S. 218 f.

14 Jahrbücher Johannes Lindenblatts oder Chronik Johannes von der Pusilie, Officials zu Riesenburg, hg. von Johannes Voigt u. Friedrich Wilhelm Schubert, Königsberg 1823, S. 93.

15 Scriptores rerum Prussicarum. Die Geschichtsquellen der Preußischen Vorzeit bis zum Untergange der Ordensherrschaft, Bde. 2, 3, hg. von Theodor Hirsch/Max Töppen/Ernst STREHLKe, Leipzig 1863, 1866, unveränd. ND Frankfurt/M 1965, Bd.6, hg. von Walther Hubatsch, bearb. von Udo Arnold, Frankfurt am Main 1968 (künftig SRP + Bd.).

16 Die Chronik Wigands von Marburg, in: SRP 2, S. 429-800, hier S. $651 \mathrm{f}$.

17 Johanns von Posilge, Officials von Pomesanien, Chronik des Landes Preussen, in: SRP 3, S. 13-464, hier S. 189. 
Ältere Hochmeisterchronik ${ }^{18,}$ die Thorner Annalen ${ }^{19}$ sowie die „Annalistische[n] Aufzeichnungen des Deutschen Ordens im 14. Jahrhundert" ${ }^{\text {20 }}$. Der württembergische Historiker Oswald Gabelkover ${ }^{21}$ berichtete kurz darüber in seiner im 17. Jahrhundert verfassten Württembergischen Geschichte, wobei er die Preußenreise Eberhards falsch auf 1397 oder 1398 datierte ${ }^{22}$.

Für die Preußenreisen gibt es auch Zeugnisse nichtschriftlicher Art. So wurden von vielen Gästen Wappen im Dom von Königsberg zur Erinnerung und Selbstdarstellung angebrach ${ }^{23}$. Doch gibt es weder einen Nachweis über ein württembergisches Wappenschild im Königsberger Dom noch über ein anderes derartiges Zeugnis der Preußenreise ${ }^{24}$. Sollte es solche Repräsentationszeugnisse gegeben haben, so haben sie die Zeiten nicht überdauert.

Der Sekundärliteratur ist dann Johann Ulrich Steinhofers „Neue Württembergische Chronik“ zuzurechnen, in die Gabelkovers Überlieferung übernommen und die falsche Datierung auf 1398 eingeengt wurde ${ }^{25}$. Christian Friedrich Sattler übernahm dann die Schilderung Steinhofers - allerdings ohne Datierung - in seine Darstellung der württembergischen Geschichte ${ }^{26}$. Johannes Voigt erwähnte die Preußenfahrt im 1834 erschienenen sechsten Band seiner Geschichte Preußens ${ }^{27}$. In der Folge ging erwähnter Christoph Friedrich von Stälin kurz auf die Preußenreise Eberhards ein ${ }^{28}$. Der württembergische Historiker Theodor Schön, der auch auf die in den „Scriptores Rerum Prussicarum“ und in der Edition des Tressler-

18 Die Ältere Hochmeisterchronik, in: SRP 3, S. 519-725, hier 625.

19 Franciscani Thorunensis Annales Prussici, in: SRP 3, S. 13-464, hier S. 188.

20 In SRP 6, S. 61-67, hier S. 66: uff die czeit was der Herre von Wirtenberg in dem Lande czu Prusen und reysten ken Sameithen.

21 WLB Cod. hist. $2^{\circ} 587$ Bl. 195 r.

22 Gabelkover (WLB Cod. hist. $2^{\circ} 587$ Bl. 195 r) hatte sich auf ein auf den 1. August 1398 datiertes Schriftstück in einem schiedsgerichtlichen Verfahren bezogen, HStA Stuttgart A 602 U 4678. Nach diesem Dokument hatten nämlich markgräflich-badische Amtsleute während der Abwesenheit Eberhards württembergische Untertanen in Dornstetten und Baiersbronn angegriffen, verschleppt und ausgeplündert. Gabelkover datierte die Abwesenheit Eberhards fälschlicherweise kurz vor diesem Ereignis, was schon ScHöN 1903 (wie Anm.11) S. 85 als Fehler aufgefallen ist. Überhaupt hatte Gabelkover gewisse Schwierigkeiten mit dieser Textstelle, so löste er die in der Urkunde stehende Ortsnamennamensvariante von Baiersbronn mit „Bayersdorf“ auf.

23 Werner Paravicini, Die Preussenreisen des europäischen Adels, Teil 1-2 (Beihefte der Francia 17/1-2), Sigmaringen 1989, 1995, hier Bd.1, S. 335.

${ }^{24}$ Ebd., S. 335.

25 Johann Ulrich Steinhofer, Ehre des Herzogthums Wirtenberg in seinen durchlauchtigsten Regenten, oder Neue Wirtembergische Chronik, Teil 2, Tübingen 1746, S. 549.

26 Christian Friedrich SatTlen, Geschichte des Herzogthums Würtenberg unter der Regierung der Graven, 2. Teil, Tübingen, 2. Aufl. 1775, S. 23.

${ }_{27}$ Johannes VoIgt, Geschichte Preussens von den ältesten Zeiten bis zum Untergange der Herrschaft des Deutschen Ordens, Bd.5, 6, 7, Königsberg 1832, 1834, 1836, hier Bd.6, S. 2 f.

${ }^{28}$ StäLIn (wie Anm. 10) S. 358 u. Anm. 4. 
buchs veröffentlichten Quellen zurückgreifen konnte, publizierte in den Jahren 1902 bis 1905 eine Reihe von Artikeln über die Beziehungen Württemberg zur preußischen Ordensherrschaft ${ }^{29}$, wobei er sowohl auf die Preußenreise Eberhards als auch auf die Beziehungen nach 1393 einging ${ }^{30}$. In seinem Standardwerk über die Preußenreisen thematisierte schließlich Werner Paravicini unter verschiedenen Aspekten die Preußenreise des württembergischen Grafen ${ }^{31}$. In jüngster Vergangenheit fand das Thema Berücksichtigung in der Dissertation von Barbara Hammes sowie jener des Verfassers ${ }^{32}$.

\section{Eberhards Preußenreise und ihr Kontext}

Bevor näher auf die Preußenreise Eberhards eingegangen werden wird, sollen zunächst kurz das Phänomen der Preußenreisen sowie deren Einbettung in den geschichtlichen Zusammenhang erörtert werden: Nachdem Akkon 1291 gefallen war, boten die Preußenreisen eine neue Möglichkeit, um an einem Kreuzzug teilzunehmen $^{33}$. Denn nach der Unterwerfung (1231-1285) ${ }^{34}$ und Zwangschristianisierung der baltischen Bevölkerung des preußischen Ordenslandes (Pruzzen) war Litauen als letztes heidnisches Land Mitteleuropas übriggeblieben. Der Deutsche Orden versuchte nun auch Litauen zu unterwerfen, zugleich war jedoch dessen heidnische Existenz wiederum eine Legitimationsgrundlage für das Fortbestehen des Ordens, der seine Berechtigung eben aus dem Kampf gegen Nichtchristen be$\operatorname{zog}^{35}$. Etwa ein Jahrhundert lang, vom Beginn des 14. bis zum Beginn des 15. Jahrhunderts ${ }^{36}$, fiel der Deutsche Orden deshalb in zahlreichen periodisch wiederkehrenden Kriegs- und Plünderungszügen in Litauen ein ${ }^{37}$. Ziel war es, Litauen zu verheeren sowie Burgen dort zu errichten oder zu erobern ${ }^{38}$. Im Gegensatz zu Plünderungszügen im Rahmen von Fehdeunternehmungen im Reich, wo die wirtschaftliche Schädigung des Gegners im Vordergrund stand, verliefen diese Aktio-

29 SCHÖN 1903-1905 (wie Anm. 11).

30 Schön 1903 (wie Anm. 11) S. 45-48, 85 ff., 153, 155.

31 Paravicini (wie Anm. 23), Bd.1, S. 25 Tab./11, S. 84 f. Anm. 321, S. 147 Tab. 12/8, S. 149

Tab. 12/87, S. 151 Tab. 13, S. 180 u. Tab. 24/43, S. 181, 215 u. Anm. 160 a, S. 329 Anm. 516;

Bd.2, S. 38 Tab. 49/259.

32 Florian (wie Anm.1) S. 16 f., 88 f.; Hammes (wie Anm. 8) S. 57, 79.

33 Claudia Brinker, Von manigen helden gute tat. Geschichte als Exempel bei Peter Suchenwirt (Wiener Arbeiten zur germanischen Altertumskunde und Philologie 30), Bern u.a. 1987, S. 107.

34 H. Boockmann, Deutscher Orden, in: LexMa 3, Sp. 768-777, hier Sp. 772.

35 Ebd., Sp.773f.

36 Paravicini (wie Anm. 23), Bd.1, S. 11.

37 Siehe Aufzählung der Züge bei Paravicini (wie Anm.23), Bd.2, S.20-41.

38 Ebd., S. 56-64. 
nen für die Überfallenen ungleich blutiger, sie wurden dabei auch gezielt getötet ${ }^{39}$. Aus dem Reich, aus Westeuropa und anderen Teilen Europas kamen Adlige nach Preußen, um den Orden bei seinem Kampf gegen die Litauer zu unterstützen ${ }^{40}$. Dieser Zug der Adligen in das Ordensland wurde - wie schon oben angedeutet als Preußenreise bezeichnet, der eigentliche Kriegszug nach Litauen dann als Reise bzw. als Litauerreise benannt ${ }^{41}$. Reise hat hier die Bedeutung von Kriegszug ${ }^{42}$. Die Preußenreisen wurden schon in der damaligen Zeit kritisiert wie etwa durch den bürgerlichen Spruchdichter Heinrich den Teichner (* um 1310, †1372/78) ${ }^{43}$.

Eberhards Preußenreise hatte auch gewissermaßen eine Familientradition. Denn laut der Chronik Peters von Dusberg war unter den Teilnehmern einer Preußenreise um 1328/1329 auch ein Graf de Wirtenbergk ${ }^{44}$ gewesen. Dieser Zug hatte eine exklusive Teilnehmerschar gehabt, an der Spitze König Johann von Böhmen ${ }^{45}$. Bei dem nicht genauer genannten Grafen wird es sich mit größter Wahrscheinlichkeit um Ulrich III. von Württemberg (1325-1344) gehandelt haben, den Urgroßvater Eberhards III. ${ }^{46}$. Der gleichnamige Neffe Ulrichs kommt hierfür kaum in Frage ${ }^{47}$.

Die Litauer, seit Beginn des 13. Jahrhunderts von Oberlitauen (lit. Aukstaitija) aus unter Großfürsten vereinigt ${ }^{48}$, widerstanden jedoch den Angriffen des Ordens und führten ihrerseits oft mit ähnlicher Härte Gegenangriffe auf den Orden und sein Gebiet aus ${ }^{49}$. Zugleich begannen sie unter ihrem Großfürsten Gediminas (13161341/42) zu Anfang des 14. Jahrhunderts ihren Herrschaftsbereich weit nach Osten in den russischen Raum bis nahe Moskau und dem Schwarzen Meer auszudehnen ${ }^{50}$.

\footnotetext{
39 Ebd., S. 57.

${ }^{40}$ Ebd., Bd.1, S. 11.

41 Ebd., S. 11 Anm. 2.

42 Ebd., Bd.2, S. 13.
}

43 Werner Paravicini, Die Preussenreisen des europäischen Adels, in: Historische Zeitschrift 232 (1981) S. 25-38, hier S. 36.

44 Pietro di Dusburg: Cronaca della terra di Prussia, introd. e commento a cura di Piero Bugiani (Biblioteca del Centro per il Collegamento degli Studi Medievali e Umanistici in Umbria 23), Spoleto 2012, S. 514; SСHÖN 1903 (wie Anm.11) S. 15; Paul Friedrich von Stälin, Geschichte Württembergs, Bd.1, 2, Gotha 1887, S.493; Paravicini (wie Anm. 23), Bd.1, S. 25 Tab.2/11, S. 84 f. Anm.321, S. 147 Tab.12/8.

$45 \mathrm{Zu}$ König Johanns Preußenreisen s. Paravicini (wie Anm. 23), Bd. 1, S. 27, 29, 73, 79 u. Anm. 275 (mit Quellen- und Literaturangaben), S. 80 u. Anm. 282.

46 Pietro di Dusburg (wie Anm.44) S. 516 Anm. 1356; Schön 1903 (wie Anm.11) S. 15. Zur Person s. Das Haus Württemberg. Ein biographisches Lexikon, hg. von Sönke LoRenz/Dieter Mertens/Volker Press, Stuttgart 1997, S. $29 \mathrm{f}$.

47 Zur Person des Neffen Ulrichs (* um 1300, †1321-1335) s. Das Haus Württemberg (wie Anm.46) S.32. Die einschlägige Literatur geht von Ulrich III. als dem Teilnehmer der Preußenreise aus, s. Pietro di Dusburg (wie Anm.44) S. 516 u. Anm.1356; SснӧN 1903 (wie Anm.11) S. 15.

48 Paravicini (wie Anm.23), Bd.2, S. 48.

49 Ebd., S.56f., 111.

${ }^{50}$ Hartmut Boockmann, Der Deutsche Orden. Zwölf Kapitel aus seiner Geschichte, München ${ }^{4} 1994$, S. 152. 
Gegen Ende des 14. Jahrhunderts änderten sich dann die Verhältnisse auf drastische Weise zu Ungunsten des Deutschen Ordens. Denn im Jahr 1386 hatte der litauische Großfürst Jogaila (1377/1386-1434) die polnische Thronerbin Hedwig (poln. Jadwiga, * 1373, † 1399) geheiratet und war Christ geworden ${ }^{51}$. Unter dem Namen Wladislaw II. bestieg er den polnischen Königsthron, den er bis zu seinem Tod 1434 innehaben sollte, und begann Litauen zu christianisieren. Mit der polnisch-litauischen Vereinigung entstand jetzt ein großes Herrschaftsgebilde, das im Lauf der Zeit zu einer machtpolitischen Bedrohung für den Orden werden sollte ${ }^{52}$. Zugleich verlor der Orden durch die Christianisierung Litauens seine Legitimationsgrundlage für die Heidenbekämpfung ${ }^{53}$.

Die nördlich von Preußen gelegene Landschaft Schamaiten (Niederlitauen, lit. Zemaitija) spielte in dieser Zeit und bei dem Preußenzug Eberhards eine wichtige Rolle. Zum einen hielt sich hier das Heidentum ${ }^{54}$ länger - die förmliche Christianisierung begann erst $1413^{55}$ - und zugleich war diese Region ein wichtiges Ziel der Kriegszüge des Ordens. Denn nur hier konnte der Deutsche Orden eine Landbrücke $^{56}$ zwischen Livland (heutiges Gebiet von Lettland, Estland), wo ein Zweig des Ordens herrschte, und Preußen ermöglichen. Politisch genoss Schamaiten eine relative Eigenständigkeit gegenüber Hochlitauen ${ }^{57}$.

Die Grenze zwischen dem Orden und Litauen änderte sich in dieser Zeit mehrmals. Geht man von der 1422 im Frieden von Melnosee festgelegten und bis $1919^{58}$ bestehenden Grenzen aus, dann hatte sich der Deutsche Orden im Verlauf des 14. Jahrhunderts weit darüber hinaus in Richtung Litauen ausgedehnt. Ab 1336 versuchte der Orden seinen Einflussbereich durch die Anlage von Burgen entlang der mittleren Memel (russ. Neman, lit. Nemunas) nach Osten bis in den Raum von Kaunas auszudehnen ${ }^{59}$. Auch Teile Schamaitens standen längere Zeit unter seinem

51 Dies und das Folgende nach M. Hellmann, Litauen, Litauer in: LexMa 5, Sp. $2011-$ 2016, hier Sp. 2013.

52 Die daraus sich ergebende spätere für den Deutschen Orden fatale Entwicklung war nach Boockmann (wie Anm. 50) S.173 f. noch nicht zwangsläufig.

53 Klaus Militzer, Die Geschichte des Deutschen Ordens, Stuttgart ${ }^{2} 2012$, S. 178.

54 Paravicini (wie Anm. 23), Bd.2, S. 50.

55 Urszula Borkowska, Organisation und Geistigkeit der polnischen Mission in Litauen, in: Kirchliche Reformimpulse des 14./15. Jahrhunderts in Osteuropa, hg. von Winfried Eberhard/Franz MachiLEK, Köln/Weimar/Wien 2006, S.143-156, hier S. 150 f.

56 Militzer (wie Anm. 53) S.174f.

57 Paravicini (wie Anm.23), Bd.2, S. 49; vgl. auch Robert Krumbholtz, Samaiten und der Deutsche Orden bis zum Frieden am Melno-See, in: Altpreußische Monatsschrift 26 (1889) S. $193-258,461-484 ; 27$ (1890) S. 1-84, 193-227, hier S. 12 u. Anm. 1.

58 Hans Mortensen/Gertrud Mortensen, Die Besiedlung des nordöstlichen Ostpreußens bis zum Beginn des 17. Jahrhunderts, Teil 2: Die Wildnis im östlichen Preußen, ihr Zustand um 1400 und ihre frühe Besiedlung (Deutschland und der Osten: Quellen und Forschungen zur Geschichte ihrer Beziehungen 8), Leipzig 1938, S.220.

59 Paravicini (wie Anm.23), Bd.2, S.61f. 


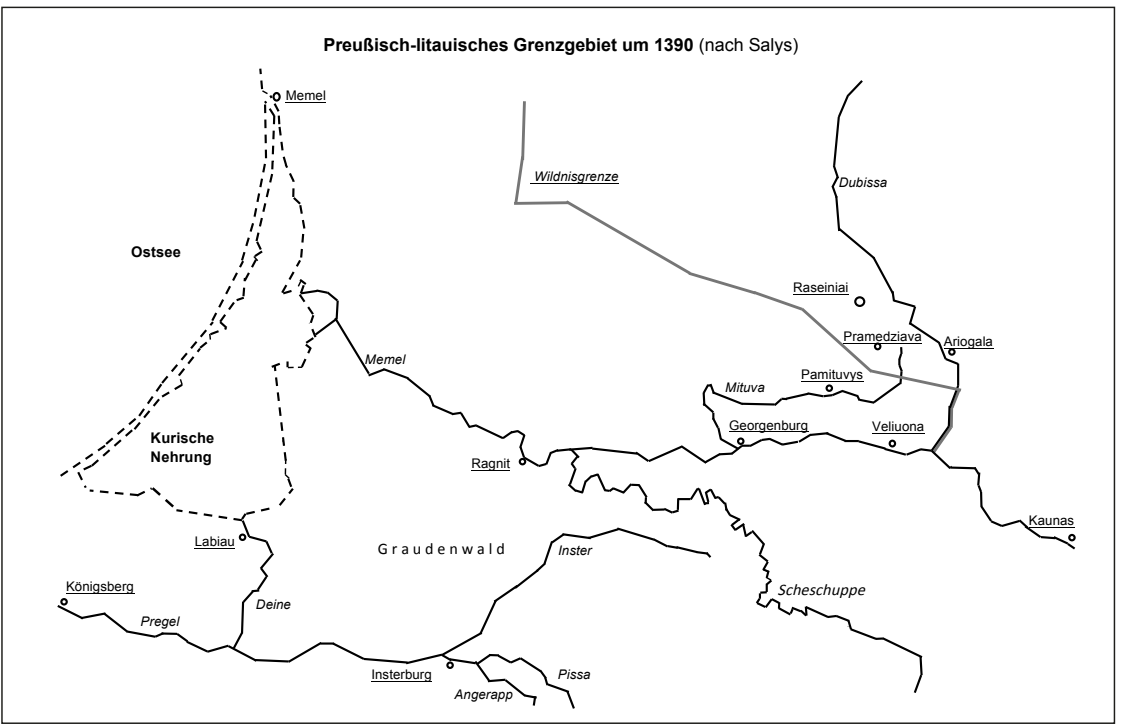

Einfluss $^{60}$. Zwischen den Siedlungsgebieten des Deutschen Ordenslandes und dem litauisch-schamaitischen Siedlungsgebiet erstreckte sich dabei um 1400 ein riesiges siedlungsleeres, allerdings nicht menschenleeres Gebiet, die sogenannte Wildnis ${ }^{61}$. Die zahlreichen Einfälle des Deutschen Ordens in dieses Gebiet dürften ein Faktor für die Entstehung der Wildnis gewesen $\operatorname{sein}^{62}$.

Die Zeit um Eberhards Preußenreise war von der Rivalität zwischen Jogaila und dessen Cousin Vytautas (poln. Witold, 1381/92-1430) geprägt. In den Auseinandersetzungen vollzog Vytautas, der zahlreiche Anhänger in Schamaiten hatte ${ }^{63}$, eine beeindruckende "Schaukelpolitik“ zwischen dem Deutschen Orden und Jogaila, mit denen er sich wechselseitig immer wieder gegen den jeweils Dritten verbündete und dann wieder rivalisierte $e^{64}$.

60 Arturas Dubonis, Das Grenzgebiet zwischen Litauen und dem Deutschen Orden: soziale, wirtschaftliche, administrative, ethnische und kulturelle Kommunikation in den Jahren 1290-1422, in: Tannenberg - Grundwald - Zalgiris 1410: Krieg und Frieden im späten Mittelalter, hg. von Werner Paravicini/Rimvydas Petrauskas/Grischa Vercamer (Deutsches Historisches Institut Warschau: Quellen und Studien 26), Wiesbaden 2012, S. 53-69, hier S. 58 .

${ }^{61}$ Zur Ausdehnung der Wildnis s. Mortensen/Mortensen (wie Anm. 58) S. 1 u. Abb. 3 und Anton Salys, Die zemaitischen Mundarten, Teil 1: Geschichte des zemaitischen Sprachgebiets, Kaunas 1930, S. 81 u. Karte.

${ }^{62}$ So Paravicini (wie Anm.23), Bd.2, S. 95 vorsichtig, während Salys (wie Anm.61) S.77f. deutlicher die Einfälle des Ordens als Ursache benennt.

63 Krumbholtz 1890 (wie Anm. 57) S.6.

64 Paravicini (wie Anm. 23), Bd.2, S. 50. 
Doch 1392 zeichnete sich zwischen Vytautas und Jogaila ein politischer Kompromiss ab, der sich letztendlich durchsetzte. Denn in jenem Jahr einigten sich Vytautas und Jogaila, indem Ersterer die Oberherrschaft seines Cousins anerkennen und zugleich dessen Statthalter in Litauen mit dem Titel eines Großfürsten werden sollte ${ }^{65}$. Nun herrschte zwischen den beiden Cousins auf der einen Seite und dem Deutschen Orden auf der anderen Seite wieder Kriegszustand, und im Sommer 1392 griff Vytautas in Litauen errichtete Ordensstützpunkte $a^{66}$. Im Herbst 1392 und Januar 1393 fanden wiederum erfolgreiche Angriffe des Ordens auf Burgen im polnisch-litauischen Machtbereich statt, wobei man jedoch keinen festen Fuß fassen konnte ${ }^{67}$.

Im Sommer 1393 herrschte dann bei gleichzeitigem formellem Kriegszustand eine gespannte Ruhe ${ }^{68}$. Stattdessen gerieten nun die Schamaiten in den Blickpunkt des Deutschen Ordens. Denn als sich Vytautas 1390 mit dem Orden gegen König Wladislaw verbündet hatte, war es ihm gelungen, die mit ihm verbündeten Schamaiten zu überzeugen, sich ebenfalls mit dem Deutschen Orden zu verbünden ${ }^{69}$. Der Orden wiederum strebte in der Folge „deren friedliche Unterwerfung “ $\mathrm{an}^{70}$. Die Integration sollte zunächst durch vertragliche Abmachungen realisiert werden $^{71}$. Als jedoch 1392 Vytautas abermals zum Feind des Ordens wurde, wendeten sich auch die Schamaiten ebenfalls gegen den Orden ${ }^{72}$.

In dieser schwierigen politischen Gemengelange unternahm 1393 Graf Eberhard seine Preußenreise. Der Aufbruch kann recht genau datiert werden. Als nämlich Eberhard am 23. April 1393 dem Gmünder Bürger Noll in Göppingen ein Lehen verlieh, wurde diese Eintragung im Lehenbuch mit dem Zusatz ergänzt: [...] als er von Land schied und gen Prussen rayt ${ }^{73}$. Es handelte sich also um eine sogenannte „Sommerreise“, welche deshalb in dieser Jahreszeit durchgeführt wurde, weil dann die Wege in Preußen und Litauen trocken und dadurch passierbar waren ${ }^{74}$.

Die Quellen geben keine Auskunft über den weiteren Weg Eberhards nach Preußen und auch nur begrenzte Auskunft über die Litauerreise. Da jedoch die

65 Z. Kiaupa, Witowt, in: LexMA 9, Sp.267-269, hier Sp.268; Voigt (wie Anm.27), Bd.5, S. 606.

${ }^{66}$ Voigt (wie Anm.27), Bd.5, S.612f. - Dadurch wurden die bisherigen Verträge zwischen Vytautas und dem Orden nichtig, ebd., S. 615.

67 Karl Heinl, Fürst Witold von Litauen in seinem Verhältnis zum Deutschen Orden in Preußen während der Zeit seines Kampfes um sein litauisches Erbe 1382-1401 (Historische Studien 165), Berlin 1925, S. 95.

68 Dies und das Folgende Heinl (wie Anm. 67) S. 104.

69 Ebd., S. 68.

70 Ebd., S. 104.

${ }^{71}$ Zum Vertrag im Jahr 1390 s. ebd., S. $68 \mathrm{f}$.

72 Krumbholtz 1890 (wie Anm. 57) S. 15.

73 Durch eine Notiz Gebhard Mehrings aus einem im Zweiten Weltkrieg verbrannten Lehenbuch überliefert in HStA Stuttgart J 2 Nr.65, 1. In der überlieferten Lehnsurkunde HStA Stuttgart A 157 U 3708 findet sich dieser Hinweis nicht.

${ }^{74}$ Militzer (wie Anm. 53) S. 177. 
Preußen- und Litauerreisen jeweils einem gleichen Muster folgten, lässt sich der Ablauf teilweise rekonstruieren. Es sind verschiedene, von den Preußenfahrern oft benutzte Routen bekannt. Eine der bekanntesten führte z. B. über Nürnberg, Prag, Breslau und Thorn ins Ordensgebiet ${ }^{75}$. Von diesen Strecken wird Eberhard eine benutzt haben. Auch über die Ankunft Eberhards im Preußenland ist nichts überliefert. Geht man vom üblichen Verlauf einer Preußenreise aus, wird er dem Ordensoberhaupt Hochmeister Konrad von Wallenrode (1391-1393) auf der preußischen Marienburg den üblichen Höflichkeitsbesuch abgestattet haben ${ }^{76}$. Dann dürfte er nach Königsberg (russ. Kaliningrad) weitergereist sein und dort am Hof des Ordensmarschalls eine längere Zeit am gesellschaftlichen Leben teilgenommen haben ${ }^{77}$. In die Zeit von Eberhards Aufenthalt im Preußen fällt übrigens der Tod Hochmeisters, der am 23. Juli 1393 starb. Der Höhepunkt der Preußenreise war dann die Litauerreise ${ }^{78}$. Zweifellos wird Eberhard von Königsberg aus zu ihr aufgebrochen $\operatorname{sein}^{79}$.

Das erste durch Quellen belegte Aufenthaltsdatum Eberhards im Ordensland fällt dann in den Zeitraum um den 15. August, als er sich schon auf dem Zug gegen die Litauer befand. Zu diesem Zeitpunkt hat er schon die Wildnis erreicht und ist im Raum zwischen Insterburg (russ. Tschernjachowsk) und dem Memelfluss (russ. Nemen) nachweisbar ${ }^{80}$. Laut der Älteren Hochmeisterchronik zogen mit ihm viele Ritter und Knechte awsz duetschen landen ${ }^{81}$. Nach den Thorner Annalen hatte Eberhard ein Gefolge von 200 Reitern bei sich ${ }^{82}$. Auch Niederländer (nedirlendir) gehörten dazu ${ }^{83}$. Es handelte sich dabei um Aufgebote u. a. aus den Komtureien Balga und Brandenburg ${ }^{84}$. Die Fahne des Heiligen Georg, das Banner der Truppe, wurde von dem fränkischen Adligen Johann von Neudeck ${ }^{85}$ (Johannes Nidecker) geführt ${ }^{86}$.

75 Vgl. Paravicini (wie Anm. 23), Bd. 1, S.262, Tab. 39/Nr. 3.

76 Vgl. Paravicini (wie Anm. 43) S. 25-38, hier S. 31.

77 Vgl. ebd., S.31.

78 Paravicini (wie Anm.23), Bd.2, S. 13.

79 Vgl. Paravicini (wie Anm. 43) S. 31.

80 Johann von Posilge (wie Anm.17) S. 189.

81 Ältere Hochmeisterchronik (wie Anm. 18) S. 625.

82 Franciscani Thorunensis Annales Prussici (wie Anm. 19) S. 188.

83 Ältere Hochmeisterchronik (wie Anm. 18) S.625.

84 Vgl. G. Bujack, Die littauischen Kriegsreisen des deutschen Ordens im 14. Jahrhundert. Nach der Chronik eines Zeitgenossen, in: Zeitschrift für preussische Geschichte und Landeskunde 4 (1867) S.655-681, hier S. 662.

85 SснӧN 1903 (wie Anm.11) S. 48 ordnet den Genannten den Herren von Neudeck zu. Die von Neudeck (auch Neideck) hatten ihre Stammburg in Langenbeutingen, Gde. Langenbrettach, Landkreis Heilbronn, vgl. Walther Ludwig, Das Geschlecht der Herren von Neideck bis um 1500, in: Württembergisch Franken 68 (1984) S. 63-96, hier S. 63 f. Möglicherweise handelte es sich bei dem genannten Johannes von Nidecker um den 1394-1425 nachweisbaren Hans I. von Neideck, s. ebd., S. 86, 95. Zur Person s. auch Wigand von Marburg (wie Anm.16) S.651 Anm.1988.

86 Wigand von Marburg (wie Anm.16) S. 651. 
Unzutreffend ist die Überlieferung der „Preussischen Chronik“ Simon Grunaus, wonach 1391 unter anderem ein Rupertus graff zu Wirtenberg mit anderen adligen Gästen am Ehrentisch, der damals in Neu-Kaunas ausgerichtet wurde, teilgenommen hätte ${ }^{87}$. Der Ehrentisch war ein festliches Essen, das der Hochmeister oder der Ordensmarschall für ihre adligen Gäste ausrichteten ${ }^{88}$, wobei zum Ehrentisch im engeren Sinne nur Ritter eingeladen wurden ${ }^{89}$. Tatsächlich wurde während des Kriegszugs des Ordens gegen Litauen im September 1391 ein Ehrentisch auf der Memelinsel, wo einst die Burg Alt-Kaunas gelegen hatte, ausgerichtet ${ }^{90}$. Auch sind zwei der bei Grunau genannten Adligen in den Quellen namentlich belegbar ${ }^{91}$, doch über einen Aufenthalt von Eberhard von Württemberg in Preußen im Jahr 1391 gibt es keinen Nachweis ${ }^{92}$.

Bevor der weitere Weg Eberhards geschildert wird, ist zunächst zu klären, wohin die Kriegsreise überhaupt gehen sollte. Laut der Älteren Hochmeisterchronik traf der Überfall die Länder Pomedien (Pomedyen) und Rossiene ${ }^{93}$ (Rossigen) $)^{94}$. Dabei muss es sich um Gebiete handeln, deren Hauptorte mit den heutigen litauischen

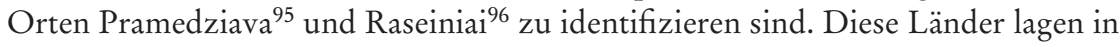
der Nähe der schamaitischen Siedlungsgrenze zur Wildnis ${ }^{97}$.

87 Simon Grunau's preussische Chronik, hg. von M. Perlbach, Bd.1 (Die Preussischen Geschichtschreiber des 16. und 17. Jahrhunderts 1), Leipzig 1876, S. 676. Nach Grunau nahmen daneben noch Fridericus marggraf zu Meissen, [...] Hindelmudus graff zu Duglas ausz Schottland, Rudeldus graff ausz Engellandt teil.

${ }^{88}$ Zum Ehrentisch s. Paravicini (wie Anm. 23), Bd.1, S. $322 \mathrm{ff.}$

89 Ebd., S. 324.

90 Ebd., S.318.

$91 \mathrm{Zu}$ den Nachweisen von Markgraf Friedrich von Meißen und eines Grafen Douglas ebd., S. 149, 318.

92 Dazu Voigt (wie Anm. 27), Bd. 5, S. 595 Anm. 2.

93 Die Schreibweise richtet sich nach Paravicini (wie Anm.23), Bd.2, S. 38.

94 Ältere Hochmeisterchronik (wie Anm.18) S.625. Pomedien und Rossyeyn nach Johann von Posilge (wie Anm. 17) S. 189.

95 Die Gleichsetzung Pomediens mit Pamituvys durch den Herausgeber von Johann von Posilge (wie Anm. 17) S.189 Anm.2 u. Gertrud Mortensen, Beiträge zu den Nationalitäten- und Siedlungsverhältnissen von Preußisch-Litauen, Berlin 1927, S.63, ist nach SALYS (wie Anm.61) S. 63 falsch, vielmehr ergibt sich nicht zuletzt aus den „Litauischen Wegeberichten“ (Chronik Wigands von Marburg, Beilage 1), in: SRP 2, S.662-711, hier S.676, dass das gesuchte Pomedien zwischen Rossiene und Erogeln (Ariogala) lag und es sich somit nur um das fünf Kilometer südlich von Girkalnis gelegene Pramedziava handeln kann. Es liegt zugleich etwa 15 Kilometer nordöstlich von Pamituvys. Die Wegeberichte dienten kriegerischen Zwecken und waren aufgrund der Aussage von Gewährsleuten angefertigte Beschreibungen von Verbindungswegen nach Litauen, vgl. Alfred Thomas, Litauen nach den Wegeberichten im Ausgange des vierzehnten Jahrhunderts, in: Königliches Realgymnasium zu Tilsit. Jahresprogramm 41 (1885) S. 1-16, hier S. 2.

96 Die historische Landschaft erstreckte sich auf jeden Fall in südlicher Richtung bis jenseits des Bebirvas, einem Nebenfluss der Saltuona, Salys (wie Anm.61) S.64.

97 Vgl. Karte ebd. 
Zunächst verlief die Litauerreise im Sommer 1393 nach dem Aufbruch in Königsberg wohl über die übliche Strecke auf dem rechten Ufer der Pregel (russ. Pregolja) flussaufwärts in Richtung Insterburg (russ. Tschernjachowsk) ${ }^{98}$. Möglicherweise wurde dabei eine Route gewählt, welche auch Herzog Albrecht III. (1365-1395) von Österreich auf seiner, vom Wappendichter Peter Suchenwirt (* um 1320, † nach 1395) geschilderten, Preußenreise 1377 genommen hatte und die über Insterburg führte ${ }^{99}$. Nahmen die Preußenfahrer 1393 diesen Weg, dann werden in Insterburg, dem Grenzort zur Wildnis und üblichen Sammelort, weitere Truppen zu ihnen gestoßen sein ${ }^{100}$. In den Quellen zu Eberhards Litauerreise wird nämlich ein - üblicherweise an solchen Zügen teilnehmendes - Insterburger Aufgebot erwähnt, das an der Aktion beteiligt gewesen war ${ }^{101}$.

Wenn Eberhard über Insterburg gezogen ist, dann hat er nach dem Aufbruch von diesem Ort nicht die übliche Richtung nach dem Ort Ragnit (russ. Neman) gewählt, sondern ist in Richtung des Flusses Scheschuppe (russ. Sesupe) abgebogen ${ }^{102}$. Die auf Insterburg folgende Wegstrecke durch die Grauden ist dann durch den Ordenschronisten Wigand von Marburg bezeugt, welcher die Durchquerung des Graudenwalds (veniunt ad Grauden) durch Eberhard geschildert hat ${ }^{103}$. Grauden bezeichneten im Preußenland unwegsame Waldgebiete ${ }^{104}$. In diesem Fall ist darunter das Große Grauden oder Graudenwald genannte Waldgebiet zwischen Pregel und Memel zu verstehen ${ }^{105}$.

Eberhard wäre entsprechend nicht mitten durch diesen Grauden geritten, sondern hätte eher dessen östliche Ausläufer passiert ${ }^{106}$. Dieser Abschnitt des Grauden war „grundlos morastig“107. Wigand beschreibt den Weg als tief (via profunda), er musste daher für die Truppe, mit der Eberhard zog, befestigt werden (planantes) ${ }^{108}$. Hier ist wohl an Knüppeldämme oder Reisigauffüllungen zu denken, welche erst ein Fortkommen ermöglichten ${ }^{109}$.

98 Vgl. Paravicini (wie Anm.23), Bd.2, S. 92.

99 Aus Peter Suchenwirt, Heinrich dem Teichner und anderen deutschen Dichtern, in: SRP 2, S.155-178, hier S. 164; vgl. Brinker (wie Anm. 33) S. 110.

100 Paravicini (wie Anm.23), Bd.2, S. 77.

101 Wigand von Marburg (wie Anm. 16) S. 652.

102 Vgl. Johann von Posilge (wie Anm.17) S.189 u. Paravicini (wie Anm.23), Bd.2, S. 92 .

103 Wigand von Marburg (wie Anm. 16) S. 651.

104 Friedrich Mager, Der Wald in Altpreussen als Wirtschaftsraum, Bd.1 (Ostmitteleuropa in Vergangenheit und Gegenwart 7/1), Köln/Graz 1960, S.149f. Möglicherweise bezieht sich der Begriff auf Flachlandwälder mit torfigen Bodenschichten, ebd., S. 150.

105 Die bei Mager, ebd., S. 149 u. Karte I genannten zwei Namensvarianten.

106 Vgl. dazu Litauische Wegeberichte (wie Anm. 95) S. 665 f. Anm. 14.

107 Paravicini (wie Anm.23), Bd.2, S. 90.

108 Wigand von Marburg (wie Anm. 16) S. 651.

109 Paravicini (wie Anm. 23), Bd. 2, S. 90. 
Bevor das Heer den Memelfluss erreichte, traf es nach dem 15. August auf den Ordensmarschall Werner von Tettingen $(* \text { um } 1350, \dagger 1413)^{110}$. Dieser hatte sich am genannten Tag wiederum mit Vytautas und dessen Cousin Skirgaila (" um 1354, $\dagger$ 1397) getroffen, um einen Gefangenenaustausch durchzuführen ${ }^{111}$. Ort der Zusammenkunft Werners und der litauischen Fürsten war die Memelinsel Tobisin (werder Tobysen $)^{112}$ gewesen ${ }^{113}$. Sie lag auf der Höhe der Einmündung der Dubissa (lit. Dubysa) in die Memel ${ }^{114}$. Nach dem Treffen auf der Memelinsel war Werner seinen Gästen entgegen gezogen. Erst durch die Zusammenkunft auf der Insel Tobisin wird die Litauerreise Eberhards zumindest ungefähr auf die zweite Augusthälfte datierbar. Der Treffpunkt der Preußenfahrer mit dem Ordensmarschall lässt sich aus den Quellenangaben nicht ermitteln, er muss irgendwo auf dem Weg zur Memel gelegen haben. Historisch gesichert ist auch die Überquerung der Scheschuppe. Posilge erwähnt eyn rytende heer uf der Suppe mit den gestin ${ }^{115}$. Wie der Fluss dann überquert wurde, wird nicht erklärt. Doch wird er zweifellos, wie bei Suchenwirt beschrieben, mit Hilfe von Pionierbrücken überwunden worden $\operatorname{sein}^{116}$.

Dann erreichte das Heer die Memel ${ }^{117}$. Auch die Stelle der Memelüberquerung ist in den Quellen nicht überliefert. Der Mitherausgeber der „Scriptores rerum Prussicarum“ Theodor Hirsch vermutete, dass Eberhard und das Heer bei Ragnit die Memel erreicht und dort die Schiffe betreten hätten ${ }^{118}$. Doch das ist eher unwahrscheinlich, denn der Weg über die Scheschuppe hätte dann einen beschwerlichen Umweg bedeutet. Der gewöhnliche Weg von Insterburg nach Ragnit verlief weiter westlich und mied die Scheschuppe ${ }^{119}$. Das Heer, zu dem Eberhard gehörte, muss also östlich von Ragnit und der Einmündung der Scheschuppe in die Memel Letztere erreicht haben.

An der Memel traf dann die Streitmacht auf eine Schiffsflotte, die Proviant mitführte ${ }^{120}$. Die Flotte war zweifellos, wie bei solchen kombinierten Land- und

110 Ältere Hochmeisterchronik (wie Anm. 18) S. 625.

111 Ebd., S. 625; zum Treffen s. auch HeInL (wie Anm. 67) S. 104.

112 Ältere Hochmeisterchronik (wie Anm. 18) S. 625.

113 Westlich der Einmündung der Dubissa in die Memel, SAlys (wie Anm. 61) S. 41.

1141382 war dem Orden der Besitz Schamaitens bis zur Dubissa dem Deutschen Orden versprochen worden, PARAvicini (wie Anm.23), Bd.2, S. 50, 52.

115 Johann von Posilge (wie Anm.17) S. 189.

116 Suchenwirt (wie Anm. 99) S. 164; vgl. Paravicini (wie Anm. 23), Bd.2, S. 92.

117 Wigand von Marburg (wie Anm. 16) S. 651.

118 Ebd., S.651 Anm. 1989.

119 Siehe dazu Friedrich Benninghoven, Die Burgen als Grundpfeiler des spätmittelalterlichen Wehrwesens im preußisch-livländischen Deutschordensstaat, in: Die Burgen im deutschen Sprachraum. Ihre rechts- u. verfassungsgeschichtliche Bedeutung, hg. von Hans Patze, Bd.1 (Vorträge und Forschungen 19), Sigmaringen 1976, S. 565-601, hier S. 601.

120 Wigand von Marburg (wie Anm.16) S.651. 
Flussunternehmungen des Ordens üblich, ${ }^{121}$ von Labiau (russ. Polessk) vom Kurischen Haff aus in die Memel eingefahren und dann flussaufwärts gefahren. Vermutlich war das im Bericht Wigands erwähnte Ragniter Aufgebot ${ }^{122}$ in Ragnit zugestiegen. Nach Theodor Hirsch soll die Flotte dann die Truppen flussaufwärts bis Georgenburg ${ }^{123}$ transportiert und am nördlichen Ufer abgesetzt haben ${ }^{124}$. Das impliziert auch, dass die Flotte bei Georgenburg festgemacht hat. Nach der Ladung betraten die Kreuzfahrer einen tiefen und unwegsamen Wald (silvam profundam et inviam) wie es in der Chronik Wigands von Marburg heiß $\mathrm{t}^{125}$. Der weitere Weg des Heeres wird von den Chronisten nicht genauer beschrieben.

Die Lokalisierung des Landeortes der Schiffe bei Georgenburg durch den genannten Theodor Hirsch basiert wohl auf den Ereignissen im Frühjahr 1394, als abermals eine Litauerreise gegen Rossiene unternommen wurde, Vytautas daraufhin einen Gegenangriff unternahm und mit einem großen Heer gegen Georgenburg vorrückte ${ }^{126}$. Hirsch folgerte daraus, dass die Flotte der Ordensstreitmacht 1394 ebenfalls bei Georgenburg gelegen hatte. Offenbar zog er dann auch für die Litauerreise des Sommers 1393 die gleiche Schlussfolgerung hinsichtlich des Landeplatzes der Ordensflotte.

Auf der Grundlage dieser These nahm Hirsch dann weiter an, dass Eberhard und die anderen Teilnehmer der Litauerreise von 1393 von Georgenburg aus die Route des in den „Litauischen Wegeberichten“ beschriebenen Wegs Nr.19 genommen hätten ${ }^{127}$. Dieser für die Teilnehmer an den Litauerreisen verhältnismäßig ungefährliche Weg führte von einem Wint genannten Wald nach Pomedien ${ }^{128}$. Demnach wäre der Weg Eberhards und der anderen Preußenfahrer von Georgenburg aus, in dessen Nähe Hirsch westliche Ausläufer des Waldes Wint lokalisierte, in die

121 Paravicini (wie Anm.23), Bd.2, S.77. Die Annahme von Brinker (wie Anm.33) S.111, dass vor 1405 Labiau nicht als Hafen für die Binnenflotte diente, weil die Deime erst in jenem Jahr schiffbar gemacht wurde, stimmt nicht, s. Paravicini (wie Anm.23), Bd.2, S.77 u. Anm. 266.

122 Wigand von Marburg (wie Anm. 16) S. 652.

123 Die Bezeichnung der Georgenburg östlich der Wildnis wechselte im Lauf der Geschichte und wurde auch für verschiedene Burgen verwandt, denn nachdem die 1258 gegründete, im darauf folgenden Jahr zerstörte und 1336 wiederaufgebaute Georgenburg (beim heutigen Jurbarkas) 1384 abermals zerstört wurde, verlegte man 1387 die flussaufwärts gelegene Beierburg samt Namen auf deren Stelle, Paravicini (wie Anm.23), Bd.2, S.60f. u. Anm. 148. Eine weitere Georgenburg wird im litauischen Land Mediniken vermutet, ebd., S.60f. Anm.148. Dann soll es eine Georgenburg (Jurgenburc) gegeben haben, bei der es sich um die Vorgängerburg der Ordensfeste Marienburg bei Veliuona handelte, deren Name jedoch nur um das Jahr 1336 auftaucht, SAlys (wie Anm. 61) S. 54.

124 Wigand von Marburg (wie Anm. 16) S.652 Anm. 1990.

125 Ebd., S. 652.

126 Ebd., S. 653 u. Anm. 2212.

127 Litauische Wegeberichte (wie Anm. 95) S. 675 f.

128 Ebd., S.676 Anm.1. Demnach konnte man den Weg bie sunnenschyn passieren, die Angreifer mussten also nicht nachts reiten, dazu SALYs (wie Anm.61) S. 81. 
Gegend des heutigen Pamituvys verlaufen, das nordöstlich von Georgenburg (lit. Jurbarkas) liegt. Doch hat Hirsch das Angriffsziel sowie den Weg dorthin offenbar falsch lokalisiert. Wie oben ausgeführt, war das erste Ziel des Angriffs wohl nicht das Gebiet um das heutige Pamituvys, sondern um das heutige Pramedziava, das rund 35 Kilometer Luftlinie (nordöstlich) von Georgenburg und 15 Kilometer Luftlinie (nordöstlich) von Pamituvys entfernt liegt. Schließlich begann der Weg Nr.19 nicht in Georgenburg, sondern wahrscheinlich im Raum von Veliuona, wo die westliche Grenze des Waldes Wint verlief, und führte von dort aus nach Pomedien bzw. Pramedziava ${ }^{129}$.

Wenn das Ordensheer tatsächlich den Weg Nr.19 benutzt hat, dann ist es vielleicht entweder bei Georgenburg von der Schiffsflotte über den Fluss gesetzt worden und dann nördlich des Memelufers ${ }^{130}$ von Georgenburg aus bis in den Raum Veliuona geritten, oder es hat erst bei Veliuona die Schiffe verlassen und ist dort an Land gegangen. Die Memel war nämlich bis Junigeda (bei Veliuona) schiffbar ${ }^{131}$. Von Raum Veliuona aus wäre die Streitmacht dann nach Norden in Richtung Pomedien gezogen. In beiden Fällen wäre die Flotte an ihrem Landeplatz zurückgeblieben. Möglicherweise legte die Flotte 1393 keine längere Flussstrecke zurück, sondern setzte das Heer aufgrund seiner Größe - dessen Zahl lag vermutlich im unteren vierstelligen Bereich, dazu kamen die Pferde - nur über ${ }^{132}$.

Letztendlich bleibt der genaue Verlauf des Weges der Ordensstreitmacht und Eberhards im Sommer 1393 spekulativ. Gesichert sind lediglich die Durchquerung der Grauden, die Überquerung der Scheschuppe und die Ankunft an der Memel sowie die Überquerung bzw. Fahrt auf derselben.

Die Aufstellung der Truppe beim Eindringen in das litauische Gebiet wird dann wieder in den Quellen erwähnt. Sie entsprach der üblichen Aufstellung bei Litauerreisen ${ }^{133}$. Nach der Chronik Wigands marschierten die Witinger, dies waren Dienstleute des Ordens ${ }^{134}$, in einer eigenen Abteilung voran, dann kamen die

129 So überzeugend argumentierend Salys (wie Anm.61) S.73. Auch Mortensen (wie Anm. 95) S. 63 u. Karte vermutet die Gegend von Veliuona als Ausgangspunkt des Weges.

130 Auf seinem Rückweg zurück von der Belagerung von Kaunas (1394) nahm das zurückkehrende Ordensheer den Weg nördlich der Memel bis Georgenburg, Voigt (wie Anm.27), Bd.6, S.31.

131 Paravicini (wie Anm.23), Bd.2, S. 52 Anm.70. Junigeda war die zeitgenössische Bezeichnung der deutschen Chronisten für Veliuona, SALYs (wie Anm. 61) S. 48.

132 Als Beispiel der Übergang des Heeres über die Memel bei der Litauerreise Herzog Albrechts von Österreich vgl. Paravicini (wie Anm.23), Bd.2, S. 92. Für die große Sommerreise 1405 wird die Gesamtstärke des Heeres auf etwa 5.000 geschätzt, ebd., S. 156. Die gesamte Flussschiffflotte des Ordens hingegen zählte um 1404 ganze 114 Schiffe, ebd. S. 92.

${ }_{133} \mathrm{Zu}$ der Reihenfolge der Aufgebote s. ebd., S.140.

134 Sie waren meist pruzzischer Abstammung, zu den Witingern s. M. Toeppen, Einige Reste der altpreußischen Sprache nebst antiquarischen Bemerkungen, in: Altpreußische Monatsschrift 4 (1867) S. 136-156, hier S. 141 ff. 
Aufgebote von Ragnit und Insterburg ${ }^{135}$. Ihnen wiederum folgten das Aufgebot der Gäste unter dem Banner des heiligen Georg und schließlich die Truppen des Deutschen Ordens ${ }^{136}$.

Die Schamaiten waren auf diesen Überfall offenbar nicht vorbereitet ${ }^{137}$. Nach Wigand dauerten die Kämpfe den ganzen Tag bis in den Abend, und schamaitische Dörfer wurden dabei mit Schwert und Feuer verwüstet. Bei den Kämpfen wurden sowohl jugendliche als auch erwachsene Schamaiten getötet oder gefangen genommen.

Die erste Nacht verbrachte das Heer in einem befestigten und mit Wachen besetzten Lager an einem nicht näher bezeichneten Gewässer (aquam ${ }^{138}$. Nach dem Bericht Wigands hörten die Lagernden nachts Kriegsgeschrei, das aus den Wäldern tönte. Dies erinnert an einen Topos in ordensfreundlichen Berichten über die Litauerreisen. Der Topos hob dabei das Kriegsgeschrei hervor und setzte die Litauer so in einen Bezug zu wilden Tieren ${ }^{139}$. Auf diese Weise sollte ihnen die Eigenschaft von Menschen abgesprochen und damit das Kriegsunternehmen legitimiert werden.

Am folgenden Morgen begann das Heer der Eindringlinge erneut mit den Kämpfen und legte Hinterhalte, wie es in der Chronik heißt. Die Schamaiten leisteten heftigen Widerstand und überraschten einige Ordensleute, welche gerade plünderten und auflauerten, und töteten zwölf von diesen während die übrigen entkamen. Die anderen Preußenfahrer jedoch fuhren den ganzen Tag bis in die Nacht fort zu töten und zu brandschatzen. Offenbar hatten sich die Teilnehmer der Litauerreise getrennt, um die Schamaiten an verschiedenen Punkten anzugreifen ${ }^{140}$.

In der zweiten Nacht übernachteten die Eindringliche in einem gleichfalls befestigten und bewachten Lager in Rossiene. Am darauffolgenden Morgen zogen sie dann zurück zu den Schiffen, die sie an der Memel zurückgelassen hatten, versorgten sich dort mit Lebensmitteln, welche vielleicht bei dem Vormarsch in einem Depot zurückgelegt worden waren ${ }^{141}$, und übernachteten diesmal in einem unbefestigten Lager.

Am folgenden Tag bestiegen sie ihre Schiffe und fuhren die Memel abwärts in Richtung Preußen. Als Beute führten sie 400 Gefangene mit sich, die wie Wigand

135 Wigand von Marburg (wie Anm.16) S.652. Das Aufgebot aus Ragnit marschierte üblicherweise vor dem Aufgebot aus Insterburg, Bujack (wie Anm. 84) S. 662.

136 Wigand von Marburg (wie Anm.16) S. 652.

137 Folgende Schilderung der Geschehnisse vom Überfall bis zum Beginn der Rückreise nach Wigand von Marburg (wie Anm.16) S.652.

138 Ebd.

139 Dies und das Folgende bis Abschnittsende nach Brinker (wie Anm.33) S. 125.

140 Vgl. Paravicini (wie Anm. 23), Bd.2, S. $96 \mathrm{f}$.

${ }^{141} \mathrm{Zu}$ dieser Maßnahme allgemein s. BuJACK (wie Anm. 84) S. 663. 
betonte, gesund bzw. unverletzt waren ${ }^{142}$. In einer anderen Quelle wird berichtet, dass zu ihrer Beute auch 700 Pferde und viel Vieh gehörten ${ }^{143}$. Vermutlich wird für die Rückreise, wie üblich, ein Teil des Heeres den Landweg benutzt haben ${ }^{144}$.

Wie bei den auswärtigen Teilnehmern von Preußenreisen üblich, verließ wohl auch Eberhard kurz danach das Ordensland und reiste in die Heimat zurück. Wann genau ist jedoch nicht klar. Auf jeden Fall war er wie bei der Hinreise eine längere Zeit unterwegs. Schon allein die erwähnte Reise von Königsberg nach Nürnberg beispielsweise konnte 25 Tage dauern ${ }^{145}$. Dazu kamen noch die Strecken von der litauischen Grenze nach Königsberg und von Nürnberg bis nach Württemberg.

Vermutlich brach Eberhard in der zweiten Septemberhälfte zur Rückreise auf, denn am 18. Oktober stellte ein Conz Staynach in Nürnberg dem württembergischen Grafen einen Lehenrevers für einen halben Hof im benachbarten Oberasbach $^{146}$ aus $^{147}$. Dies legt einen Aufenthalt Eberhards in Nürnberg nahe. Allem Anschein nach führte die Rückreise Eberhards also über Nürnberg ${ }^{148}$.

Ein Treffen Eberhards mit Herzog Leopold IV. von Österreich (1386-1411) und Markgraf Bernhard von Baden in Herrenberg zum Zweck eines Vertragsabschlusses am 15. September, was auf eine frühere Rückreise hinwiese, ist unwahrscheinlich ${ }^{149}$. Denn dieses Bündnisprojekt kam wohl nicht über das Planungsstadium hinaus ${ }^{150}$.

Die Litauerreise sollte jedoch nicht ohne Folgen für das Ordensland bleiben. Die Schamaiten unternahmen vor dem 16. Oktober einen Vergeltungsangriff auf die Stadt sowie die Burg Memel (lit. Klaipeda) und verbrannten die Stadt und die

142600 nach Ältere Hochmeisterchronik (wie Anm.18) S.625. Nach einer anderen Quelle sollen es 350 Gefangene gewesen sein, Wigand von Marburg (wie Anm.16) S.652. Die Gefangenen und die Beute wurden wohl mit den Schiffen abtransportiert, vgl. ebd. Zahlreiche Gefangene sollen aus einem unbekannten Ort oder Landschaft namens Hucke gestammt haben, doch wurde die geographische Bezeichnung vom Kopisten der Chronik nicht korrekt wiedergegeben, ebd., S. 652 u. Anm. 1997.

143 Ältere Hochmeisterchronik (wie Anm. 18) S.625.

144 Zur Rückkehr vgl. Paravicini (wie Anm.23), Bd.2, S. 77 f.

145 So benötigte Johann von Blois 1362/1363 acht Tag von Königsberg nach Thorn und 17 Tage von Thorn nach Nürnberg bei insgesamt fünf Ruhetagen, s. dazu ParavicinI (wie Anm.23), Bd.1, S. 262 Tab. 39/Nr.3, S. 264, Tab. 41/Nr. 4. Dazu kam noch der Weg von Litauen nach Königsberg und von Nürnberg nach Württemberg.

${ }_{146}$ Unmittelbar westlich an Nürnberg angrenzend.

147 HStA Stuttgart A 157 U 5839.

148 Dies hatte schon Gebhard Mehring erwogen, HStA Stuttgart J 2 Nr. 65, 1.

149 Regesten der Markgrafen von Baden und Hachberg 1015-1515, hg. von der Badischen Historischen Kommission, Bd. 1: Markgrafen von Baden 1050-1431, Markgrafen von Hachberg 1218-1428, bearb. von Richard FESTER, Innsbruck 1900 (künftig: RMB), Nr.1597, S.169, Nr.5001, S. $534 \mathrm{f}$.

150 Florian (wie Anm. 1) S. 123 Anm. 34. 
neuerbauten Bergfriede, lediglich die Burg konnte gehalten werden ${ }^{151}$. Der Angriff forderte etwa 60 Todesopfer darunter einen Ordensritter ${ }^{152}$. Dieses Mal zogen die Schamaiten mit reicher Beute $\mathrm{ab}^{153}$.

Die lange Abwesenheit Eberhards von Württemberg sollte sich dann für ihn als problematisch herausstellen. Territorialherren, die auf eine Preußenreise gingen, versuchten daher politische Konflikte vor Reiseantritt möglichst noch zu regeln ${ }^{154}$. So hatte Graf Eberhard am 23. April vor seinem Aufbruch zur Preußenreise einen friedlichen Ausgleich mit der Reichsstadt Gmünd getroffen ${ }^{155}$. Mit Gmünd gab es dann auch keine Probleme. Dafür kam es trotz vertraglicher Absicherung mit Baden zu Schwierigkeiten. Denn als Eberhard in Preußen weilte, griffen trotz einer seit $1392^{156}$ bestehenden Einung mit Baden, badische Amtleute die Dörfer Dornstetten und Baiersbronn an, plünderten dort und verschleppten württembergische Eigenleute. Bei späteren Verhandlungen zwischen Baden und Württemberg auf einem Schiedstag 1398 in Weil der Stadt führten die württembergischen Räte dieses Vorkommnis neben einer ganzen Reihe von anderen Beschwerden auf. In den Unterlagen heißt es darüber: Der ersten hand mins heren des marggrafen amptlúte die von dornstetten und die von Peyersbrun gefangen, die mins heren von wirtemberg aigen sind und daz ir genomen, do mine here ze pruessen waz und im land und lut enpholben bett $[\ldots]^{157}$.

Johannes Voigt hielt es im sechsten Band seiner „Geschichte Preussens“ für möglich, dass die Anwesenheit Eberhards in Preußen vielleicht noch eine ganz andere Folge gehabt hatte. Demnach wäre es „leicht möglich“ gewesen, dass die Anwesenheit des Grafen „mit mehren Mitgliedern seiner Rittergesellschaften Einfluß auf die Entstehung des Eidechsen-Bundes gehabt habe“158. Der Eidechsenbund oder auch Eidechsengesellschaft war eine 1397 im Kulmer Land gegründete und vermutlich gegen den Deutschen Orden gerichtete ritterliche Vereinigung ${ }^{159}$. Da jedoch nicht bekannt ist, ob tatsächlich Mitglieder der später geschlossenen Vereinigung Eberhards mit der schwäbischen Ritterschaft (1407) im Jahr 1393 mit in Preußen gewesen waren ${ }^{160}$, kann diese Überlegung weder bewiesen noch widerlegt werden.

151 Johann von Posilge (wie Anm. 17) S. 189; Voigt (wie Anm. 27), Bd.6, S.3.

152 Johann von Posilge (wie Anm. 17) S. 189.

153 Ebd.

154 Paravicini (wie Anm.23), Bd.1, S. 215. Zu der Abmachung mit Gmünd s. Florian (wie Anm.1) S.38.

155 Florian (wie Anm.1) S. 38.

156 Die am 5. November 1392 abgeschlossene Einung hatte eine Dauer von zehn Jahren, HStA Stuttgart A 602 U 5100; RMB 1 (wie Anm. 149) Nr.1568, S. 165.

157 (1398 Aug. 1) HStA Stuttgart A 602 U 4678; vgl. WLB Cod. hist. $2^{\circ}$ 587, Bl.195 r;

Steinhofer (wie Anm. 25) S. 549; Schön 1903 (wie Anm.11) S. 85.

158 Voigt (wie Anm. 27), Bd.6, S.148 Anm.3.

159 C. A. LüCKerATH, Eidechsengesellschaft, in: LexMa 3, Sp. 1694.

$160 \mathrm{Zu}$ den Bünden s. Florian (wie Anm. 1) Kap.4.1.-2. 


\section{Politische Kontakte}

Seit der Preußenreise Eberhards sind anhand diplomatischer Korrespondenz politische Kontakte zwischen Württemberg und dem Deutschen Orden nachweisbar. Allerdings sind mit einer Ausnahme nur Briefe des Ordens überliefert. Graf Eberhard bekam diese als Angehöriger einer Schicht europäischer Monarchen, Fürsten und Herren (Grafen und Edelfreie), deren Unterstützung der Deutsche Orden benötigte. Der Grund dafür lag in dessen schon oben geschilderter schwierigen politischen Lage seit der Vereinigung Polens mit Litauen (ab 1386). Die Lage des Ordens wurde besonders problematisch, als der wieder mit ihm verbündete Vytautas nach seiner Niederlage gegen die Tataren in der Schlacht an der Worskla am 12. August 1399 die Fronten wechselte und mit Jogaila (Wladislaw) eine neuerliche, gegen seinen früheren Bündnispartner gerichtete Allianz schloss ${ }^{161}$. Zudem hatten König Wenzel (1378-1400) 1395 und Papst Bonifaz IX. (1389-1404) 1403 den Heidenkampf verboten. Dies hatte die Legitimation des Ordens in ihrem Kern getroffen und diesen so zusätzlich geschwächt ${ }^{162}$.

Der Orden warb daher intensiv um Unterstützung aus dem Reich und dem übrigen Europa für seine Auseinandersetzung mit dem vereinigten Polen-Litauen ${ }^{163}$. Mit bisher noch nicht gekannter Intensität kämpften die beiden Parteien mit propagandistischen Mitteln, um die Gunst der europäischen Öffentlichkeit, indem sie den Gegner auf das heftigste attackierten. Der Orden stellte Jogaila und Vytautas als Heiden dar ${ }^{164}$. Der Kampf des Ordens gegen diese beiden sei daher legitim und die christlichen Fürsten müssten den Orden dabei unterstützen. Seinerseits warf Polen-Litauen dem Orden die Vernachlässigung seiner Kernaufgabe, nämlich der Christianisierung, vor.

Für die bevorstehenden Auseinandersetzungen mit Polen-Litauen benötigte der Orden neben allgemeiner politischer Unterstützung auch ganz konkret die Unterstützung durch militärische Kräfte. Doch seit etwa 1400 wurde der Zustrom an „für Gott und ritterliche Ehre kämpfenden Preußenfahrer" immer schwächer ${ }^{165}$. Der Grund war die nachlassende Attraktivität der Preußenreisen ${ }^{166}$. Söldner mussten die fehlenden Preußenfahrer ersetzen. Um die nun dringend benötigten

161 Boockmann (wie Anm. 50) S. 175 f. Die Worskla ist ein linker Nebenfluss des Dnepr (Russland, Ukraine).

162 Boockmann (wie Anm. 50) S. 173 mit Einschränkungen. Zur päpstlichen Bulle VoIGT (wie Anm.27), Bd.6, S.250ff.

163 Dies und das Folgende nach Boockmann (wie Anm. 50) S.176f.

164 Ebd., S.176.

165 Uwe Tresp, Söldner aus den Ländern der Böhmischen Krone in den Kriegen zwischen dem Deutschen Orden und Polen-Litauen zu Beginn des 15. Jahrhunderts, in: Tannenberg - Grundwald - Zalgiris 1410. Krieg und Frieden im späten Mittelalter, hg. von Werner Paravicini/Rimvydas Petrauskas/Grischa Vercamer (Deutsches Historisches Institut Warschau: Quellen und Studien 26), Wiesbaden 2012, S.135-158, hier S. 139.

166 Dazu Militzer (wie Anm. 53) S.177f. 
Söldner zu bekommen, bedurfte es erhöhter politischer und propagandistischer Anstrengungen ${ }^{167}$, denn die Anwerbung von Söldnern verlief im Spätmittelalter anders als zu späteren Zeiten, als man durch allgemeine Werbeaufrufe aus randständigen Bevölkerungsgruppen Fußsoldaten gewann ${ }^{168}$. Vielmehr wurden Söldner im spätmittelalterlichen Mitteleuropa über Kontakte zu Herrschaften oder einflussreichen Personen rekrutiert ${ }^{169}$.

Kurze Zeit nach der Preußenfahrt Eberhards sind die ersten preußisch-württembergischen Kontakte nachweisbar. Mit zahlreichen anderen Fürsten und Herren stand Eberhard quasi als Adressat im Briefverteiler des Deutschen Ordens und erhielt von diesem diplomatische Schreiben. So findet sich drei Jahre nach Eberhards Preußenreise in einer auf den Oktober 1396 datierten Liste der Schreiben, welche der Komtur von Danzig an verschiedene Fürsten und Herren mitgenommen hatte, auch der Name des württembergischen Grafen ${ }^{170}$. Eine um 1404 angelegte Übersicht der Korrespondenzpartner des Hochmeisters mit deren jeweiligen korrekten brieflichen Anschriften und Anreden spiegelt das diplomatische Umfeld deutlich wieder ${ }^{171}$. In der Anrede wurde Eberhard dabei als lieber herre bezeichnet ${ }^{172}$. Ob dies auf eine größere Nähe des Hochmeisters zu Eberhard hindeutet, ist unklar. Zumindest wird dieses Attribut in der genannten Liste sehr sparsam verwendet.

Eines der eindringlichsten Rundschreiben des Ordens, das auch an Graf Eberhard gerichtet war, stammt aus der Zeit kurz vor der Schlacht von Tannenberg und ist auf den 20. Mai 1410 datiert. Es enthält die dringende, ja geradezu dramatische Bitte des Hochmeisters Heinrich von Jungingen (1407-1410), in das Ordensland $\mathrm{zu}$ kommen und dieses gegen die Feinde der Christenheit zu schützen: und wellet gunnen euwir hochwirdikeit, heren, forsten, rittern und knechten mines ordens lande czu besuchin, welche die do gnade haben luterlich durch got, und ritterschaft czu beschirmunge der heiligen cristenheit, dorumb ich mit minen ganczen orden den almechtigen got vor euwir gelukseligk[eit] czunemen und lang leben andachtichlin bitten will ${ }^{173}$. Mit dem Appell an die religiösen Gefühle der Adressaten erweist sich das Schreiben als ein Mittel des oben geschilderten propagandistischen Kampfes des Ordens gegen Polen-Litauen.

167 Boockmann (wie Anm. 50) S. 178.

168 Tresp (wie Anm. 165) S. 141.

169 Ebd., S. 141.

170 Geheimes Staatsarchiv Preußischer Kulturbesitz, Berlin (künftig: GStA PK) XX HA, OF 2 c, p. 48.

171 GStA PK XX HA, OF 3, p. 1-6.

172 GStA PK XX HA, OF 3, p. 1-6, hier 1.

173 Codex epistolaris Vitoldi, magni ducis Lithuaniae 1376-1430, hg. von Antoni Prochaska (Monumenta medii aevi historica res gestas Poloniae illustrantia 6), Krakau 1882 (künftig CEV), Nr.440, S. 207; Voigt/Schubert (wie Anm. 14) S. 213. 
Ob der Deutsche Orden dann wirklich Hilfe von Graf Eberhard bekam, ist eher ungewiss. Im Krieg von 1410-1411 sind lediglich zwei Söldnerverbände aus Südwestdeutschland auf Seiten des Ordens belegbar; einer unter der Führung Erkingers von Seinsheim und einer unter Truchsess Konrad von Pommersfelden ${ }^{174}$. Jedoch stammten beide Verbände aus Franken ${ }^{175}$. Lediglich in einem Fall, bei einem Georg von Westerstetten, der zur Truppe Erkingers gehörte, gab es mögliche Verbindungen zu Württemberg ${ }^{176}$.

In der Folge der Niederlage des Deutschen Ordens gegen König Wladislaw und Vytautas in der Schlacht von Tannenberg am 15. Juli 1410 kam es zu Friedensverhandlungen. Diese mündeten dann in der Regierungszeit des Hochmeisters Heinrich von Plauen (1410-1413) in den Ersten Thorner Frieden vom 1. Februar 1411 ein. Im Zusammenhang mit den Verhandlungen richtete der Hochmeister immer wieder Schreiben auch an die Fürsten und Herren des Reiches um politische Unterstützung zu erhalten. So beklagte der Hochmeister in einem Schreiben vom 15. Januar 1411 das Verhalten König Wladislaws, der die Zeit des Waffenstillstands nur genutzt habe, um sich mit Truppen zu verstärken, und bat die Empfänger um Beistand zur Rettung des Ordens ${ }^{177}$. Auch Eberhard muss einen solchen Brief bekommen haben, denn der Hochmeister wiederum erhielt ein auf den 31. Januar datiertes Schreiben des Grafen. Darin bedauerte der württembergische Graf die schwierige Lage des Ordens ${ }^{178}$. Weiter versprach er auch den Orden zu unterstützen, wobei er jedoch nichts Konkretes nannte.

Der Thorner Friedensschluss am 1. Februar 1411 vermochte dann die fragile politische Lage nicht zu stabilisieren. Die Friedensbedingungen sahen zwar auf den ersten Blick nicht ungünstig aus; so musste der Orden Schamaiten an König Wladislaw und Vytautas zurückgeben, ebenso die Gebiete Zakrzew und Dobrin an Herzog Ziemowit IV. von Masowien († 1426) und Wladislaw sowie 100.000 Schock ${ }^{179}$ böhmischer Groschen zahlen ${ }^{180}$. Doch geriet der Orden durch die Ent-

174 Die Söldner unter der Führung Erkinger von Seinsheims, stammten fast alle aus Franken, s. Sven Eckdahl (Bearb.), Das Soldbuch des Deutschen Ordens 1410/1411, Teil 1-2 (Veröffentlichungen aus den Archiven Preussischer Kulturbesitz 23), Köln/Weimar/Wien 1988, 2010, S.108, 186.

175 Ebd., S. 72, 179, 297-299, 312, 339, 358 f.

$176 \mathrm{Zu}$ den Beziehungen der Familie von Westerstetten zu Württemberg s. Florian (wie Anm. 1) S. 88 Anm. 103, 265. Allerdings hatten Angehörige dieses Geschlechts auch Funktionen in der Ordensherrschaft inne, SсHÖN 1903 (wie Anm.11) S. 153.

177 Voigt (wie Anm. 27), Bd.7, S. 132.

178 GStA PK XX HA, OBA Nr. 1496; Regest in Regesta historico-diplomatico Ordinis S. Mariae Theutonicorum (1198-1525), bearb. von Erich JoAchim $\dagger$, hg. von Walther Hubatsch, Pars 1, Vol. 1 (1198-1454), Göttingen 1948, Nr.1496, S. 88; vgl. Voigt (wie Anm.27), Bd.7, S. 144 Anm.5.

179 Ein Schock hier als Zählmaß für 60 Groschen, s. Paravicini (wie Anm.23), Bd.2, S. 176 .

180 Dies und das Folgende nach Militzer (wie Anm. 53) S. 223. 
schädigungszahlungen und die allgemein verminderten Einnahmen in eine fatale Finanzsituation. Er hatte Schwierigkeiten die Entschädigungsleistungen aufzubringen. Dann wurde auch der Ausbruch neuerlicher Kämpfe erwartet ${ }^{181}$. Für diese Auseinandersetzungen benötigte der Orden wiederum bewaffnete Kräfte, entweder Preußenfahrer "alten Stils“, die auf eigene Kosten ihre Kriegsfahrt unternahmen, oder Söldner, die vom Orden bezahlt werden mussten ${ }^{182}$. Und da die Zahl der „freiwilligen“ Preußenfahrer schwand, hatte die Anwerbung von Söldnern oberste Priorität. Durch die Finanzierung von Söldnern wurde die Finanzmisere des Ordens noch verstärkt und wirkte sich in einem erheblichen Ausmaß auf dessen Politik aus ${ }^{183}$.

Die finanziellen Schwierigkeiten des Ordens sollten dann auch Graf Eberhard berühren. Zentralfigur in den jetzt aufkommenden Streitigkeiten um Gläubigerforderungen war König Sigmund. Er gehörte zu den bedeutendsten Gläubigern des Ordens ${ }^{184}$. Königin Barbara (* um 1390, $†$ 1451) forderte als Stellvertreterin ihres Mannes daher um den 24. Februar 1413 die Rückzahlung von $15.000 \mathrm{Gul-}$ den ${ }^{185}$. Dieser Betrag war wohl Teil einer Gesamtsumme von 25.000 Gulden, deren Entrichtung an König Sigmund im Januar 1412 in Ofen (ungar. Buda) ${ }^{186}$ festgelegt worden war, als Michael Küchenmeister als Abgesandter des Ordens ein Bündnis mit König Sigmund geschlossen hatte, das jedoch nicht realisiert wurde ${ }^{187}$. In einer Nebenabsprache war dabei festgelegt worden, dass der Orden zusätzlich und möglichst rasch die erwähnten 25.000 Gulden zahlen sollte und zwar 10.000 Gulden sofort und 15.000 Gulden am 22. Mai ${ }^{188}$. Der Hochmeister war in seiner Antwort an Königin Barbara grundsätzlich zur Zahlung der 15.000 Gulden bereit, wollte allerdings den Auszahlungstermin auf einen unbestimmten Zeitpunkt verschieben ${ }^{189}$.

Zudem vermochte der Orden nicht die vom König dringend verlangte Zahlung von noch ausstehenden 12.500 Schock böhmischer Groschen zu leisten ${ }^{190}$. König Sigmund hatte sich nämlich im Oktober 1412 von König Wladislaw Forderungen

\footnotetext{
181 Vgl. ebd., S. 224.

182 Ebd., S. 224, 226.

183 Ebd., S. 226.

184 (1413 Aug. 28) Wilhelm Altmann (Bearb.), Die Urkunden Kaiser Sigmunds (14101437), Bd.1 (Regesta Imperii 11), Innsbruck 1896-1897 (künftig RI), Nr.660, S. 39.

185 Voigt (wie Anm. 27), Bd. 7, S. 202 f. Vgl. (zu 1412 Februar 6) RI 11/1, Nr. 188, S. 12.

186 Heute Stadtteil von Budapest.

187 Ottokar Israel, Das Verhältnis des Hochmeisters des Deutschen Ordens zum Reich im 15. Jahrhundert (Wissenschaftliche Beiträge zur Geschichte und Landeskunde Ostmitteleuropas 4), Marburg a.d.L. 1952, S. 13.

188 Erich Weise: Die Staatsverträge des Deutschen Ordens in Preußen im 15. Jahrhundert, 1. Bd. (1398-1437), Marburg 21970, Nr. 88, S. 93.

189 Voigt (wie Anm. 27), Bd.7, S. 202 f. u. Anm. 1 (Schreiben vom 24. Mai 1413).

190 (1413 Mai 17) RI 11/1, Nr.491, S.29; Voigt (wie Anm.27), Bd.7, S. 203, der jedoch eine Summe von 13.000 Schock nennt.
} 
an den Orden von insgesamt 25.000 Schock abtreten lassen, für die er sich wiederum vom Hochmeister am 30. November 1412 eine Schuldverschreibung ausstellen ließ ${ }^{191}$. Die Rückzahlung an den König war in zwei Raten für den 2. Februar und 2. April 1413 vorgesehen ${ }^{192}$. Der Hochmeister konnte jedoch wegen der katastrophalen Finanzlage die Februarrate nicht bezahlen und hatte den König deswegen an den für die Ordensballeien im Reich zuständigen ${ }^{193}$ Deutschmeister Konrad von Egloffstein (1396-1416) verwiesen ${ }^{194}$. Dieser verweigerte in einem Schreiben an Sigmund mit Verweis auf die eigene finanzielle Bedrängnis jedoch die Bezahlung ${ }^{195}$. Der König wiederum war deswegen äußerst aufgebracht ${ }^{196}$.

Bei der sich daraus entwickelnden diplomatischen Auseinandersetzung wurde neben verschiedenen Fürsten und Herren auch Eberhard von den Kontrahenten angeschrieben. Der Deutschmeister teilte nämlich in der Folge verschiedenen Fürsten und Herren, darunter Graf Eberhard, mit, dass diese in seinem Sinne auf den Königs einwirken sollten ${ }^{197}$, indem sie Sigmund überzeugten, dass er (der Deutschmeister) die Zahlungen nicht zu übernehmen vermochte ${ }^{198}$. Einige der Adressaten hatten dann in diesem Sinne an den König geschrieben ${ }^{199}$. Der Hochmeister wirkte nun dem entgegen. Aus der Ordenskanzlei ist ein auf den 7. September 1413 datiertes Konzept eines Schreibens an die Fürsten und Herren, darunter an Graf Eberhard, überliefert ${ }^{200}$. Darin stellte der Hochmeister seine Situation dar und bat seinerseits die Empfänger auf Konrad von Egloffstein einzuwirken, damit dieser doch die Zahlung der Summe übernehme. Weitere Schreiben an Eberhard in dieser Sache sind nicht überliefert.

Letztendlich endete die Regierung des Hochmeisters Heinrich von Plauen in einem Desaster. Zwar schickte Eberhard tatsächlich um den 15. August dem Ordenshochmeister Söldner zu Hilfe ${ }^{201}$. Es handelte sich um eine überschaubare Truppe von 13 Erbar knechte ${ }^{202}$. Unter diesen waren jeweils ein Angehöriger der Familien Spet und Lichtstein, ein ebenfalls nicht namentlich genannter Sohn Konrad Schillings sowie zwei Angehörige der Westerstetten. Doch wurde dieser

191 Israel (wie Anm. 187) S. 17.

192 Weise (wie Anm. 188) Nr. 96, S. 99 f.

193 Boockmann (wie Anm.34) Sp. 770.

194 Voigt (wie Anm. 27), Bd.7, S. 203.

195 Ebd., S. 203 f.; vgl. Militzer (wie Anm. 53) S. 259.

196 Voigt (wie Anm.27), Bd.7, S. 203.

197 So laut einem Brief des Hochmeisters an die Fürsten und Herren des Reichs: (1413 September 7) GStA PK XX HA, OF 6, p. 334-336, sowie einem Schreiben an den Deutschmeister, Voigt (wie Anm. 27), Bd.7, S. 204 f.

198 (1413 September 7) GStA PK XX HA, OF 6, p. 334-336.

$199 \mathrm{Ebd}$.

200 Ebd.

201 GStA PK XX HA, OF 6, p. 346-349, hier 348. Erwähnung bei Voigt (wie Anm. 27), Bd. 7, S. 208 u. Anm. 3; Schön 1903 (wie Anm. 11) S. 155.

202 GStA PK XX HA, OF 6, p. 348. 
württembergische Söldnertrupp von König Wladislaw abgefangen und gefangengesetzt ${ }^{203}$.

Ein weiterer württembergischer Adliger namens Ottlin von Baldeck ist übrigens gleichfalls 1413 als Teilnehmer einer Preußenreise nachweisbar ${ }^{204}$. Ob Ottlin als Söldner oder als „ehrenamtlicher“ Preußenfahrer unterwegs war, ist allerdings nicht mehr erschließbar. Als schließlich der Hochmeister im Herbst 1413 einen Feldzug gegen Polen-Litauen starten wollte, enthob ihn die Führungsschicht des Ordens am 9. Oktober seines Amtes und ließ ihn gefangen setzen ${ }^{205}$.

Graf Eberhard wurde aber auch von einer weiteren Seite als wichtiger Akteur der politischen Auseinandersetzungen um den Deutschen Orden wahrgenommen. Denn nach der Absetzung Heinrichs von Plauen erhielt Eberhard von dessen Vettern Heinrich Reuss von Plauen dem Jüngeren, Herrn zu Greiz, und Heinrich, Herrn zu Plauen, ein auf den 29. November 1413 datiertes Schreiben ${ }^{206}$. Darin beklagten sie die Absetzung ihres Vetters und baten Eberhard, ihre Aufforderung an den Deutschen Orden zu einer schiedsgerichtlichen Verhandlung weiterzuleiten, da ihre direkte Aufforderung an den Orden bislang ohne Antwort geblieben war.

Der Kampf des Ordens und Polen-Litauens um die Gunst der europäischen Öffentlichkeit ging nach dem Thorner Frieden weiter. Der Deutsche Orden bemühte sich dabei seit der Zuwendung König Sigmunds zu Polen (1412) verstärkt um die Zustimmung bzw. die politische Unterstützung der Fürsten und Herren ${ }^{207}$. Denn die Fürsten und besonders die Kurfürsten waren dem Deutschen Orden gegenüber positiv eingestellt ${ }^{208}$. Intensive diplomatisch-propagandistische Bemühungen versprachen bei dieser Zielgruppe daher am ehesten Erfolg.

Der Schriftverkehr bzw. die diplomatischen Kontakte brachen daher auch nach der Absetzung Heinrichs von Plauen 1413 unter dem neuen Hochmeister Michael Küchmeister (1414-1422) nicht ab. Die Schreiben des Hochmeisters dienten auch dazu, die politische Stellung des Ordens in den Auseinandersetzungen mit Polen-Litauen im Sinne des Ordens darzustellen, für sie zu werben und Unterstützung zu bekommen. So erhielt Eberhard im Januar 1414 neben einer großen Anzahl anderer Fürsten und Herren ein Schreiben des neuen Hochmeisters ${ }^{209}$.

203 Voigt (wie Anm. 27), Bd.7, S. 208.

204 Damals verkauften die Brüder Otto und Rudolf von Baldeck u.a. im Namen des abwesenden Öttlins von Baldeck, der gen Bruessen ritt, ein Gut in Frickenhausen: (1413 Oktober 4) HStA Stuttgart A 602 Nr 14038.

205 Militzer (wie Anm. 53) S. 225.

206 Akten der Ständetage Preussens unter der Herrschaft des Deutschen Ordens, hg. von Max Töppen, Bd.1 (1233-1435), Leipzig 1878, ND Aalen 1973, Nr.182, S.277-230, hier S. 277.

207 IsRael (wie Anm. 187) S. 16.

208 Ebd., S. 16.

2091414 [Jan. 14?] GStA PK XX HA, OF 5, p. 219-221 [seit 1945 verschollen]; Regest bei Markian Pelech, Der verlorene Ordensfoliant 5 (früher Hochmeister-Registrant II) des Historischen Staatsarchivs Königsberg mit Regesten (nach Rudolf Philippi und Erich 
Darin zeigte dieser seinen Amtsantritt an, berichtete, dass ihm sein abgesetzter Vorgänger Gehorsam gelobt habe und informierte über einen Schiedstag nach Ostern mit Polen und Litauen. Vermutlich im August 1414 klagte der Hochmeister dann über einen Überfall König Wladislaws und den dadurch entstandenen Verwüstungen ${ }^{210}$. Im Dezember des gleichen Jahres bat Michael Küchmeister wieder um Unterstützung für den bedrängten Orden, explizit für seine Gesandten bei den Verhandlungen auf dem Konstanzer Konzil211.

Zwei Jahre später bekam Eberhard neben anderen Fürsten und Herren ein auf den 1. November 1416 datiertes Schreiben Küchmeisters, indem dieser der Behauptung König Wladislaws entgegentrat, „dass der Orden zu keinem Tag und keiner Einigung gebracht werden könne“212. Hintergrund war der zuvor im Oktober veranstaltete Schiedstag von Welun (Veliuona) zwischen dem Deutschen Orden und König Wladislaw von Polen sowie Großfürst Vytautas, welcher jedoch gescheitert war und die Differenzen eher noch befördert hatte ${ }^{213}$.

Auch nach dem Tod Graf Eberhards im Jahr 1417 sollte Württemberg im Kalkül des Ordens eine Rolle spielen. Dies geht aus einem auf den 6. November 1418 datierten Dokument hervor, in dem der Ablauf eines - ebenfalls in Welun veranstalteten - gescheiterten Verhandlungstermins des Hochmeisters mit König Wladislaw und Vytautas wiedergegeben wird ${ }^{214}$. Um zu retten, was noch zu retten war, schlugen die Ordensunterhändler neue Schiedsgerichte mit unterschiedlichen Zusammensetzungen vor ${ }^{215}$. Eines davon sollte neben Herzog Ludwig VII. von Bayern-Ingolstadt (1413-1447) und Markgraf Bernhard I. von Baden (†1431) auch durch Graf Eberhard IV. von Württemberg (1417-1419) besetzt sein ${ }^{216}$. Dieser Vorschlag wurde jedoch nicht aufgenommen und weiterverfolgt. Weitere Schreiben an Graf Eberhard IV. sind nicht überliefert.

Die vorgestellte diplomatische Korrespondenz zeigt, dass die Ordensherrschaft in ihrer sich seit dem Ende des 14. Jahrhunderts immer mehr zuspitzenden existenziellen Krise äußerst intensiv um politische Unterstützung warb. Die Anstrengungen gingen auch nach der Niederlage von Tannenberg weiter. Adressat ihrer Bemühungen waren europäische Potentaten und vor allem die Fürsten und Herren des Reichs, zu denen auch Eberhard gehörte. Sie bildeten die Öffentlichkeit, um welche der Deutsche Orden - in Konkurrenz zu Polen-Litauen - für sich werben musste.

Joachim), in: Beiträge zur Geschichte des Deutschen Ordens, Bd.1, hg. von Udo ARnold (Quellen und Studien zur Geschichte des Deutschen Ordens 36), Marburg 1986, S.123-175, hier Nr. 124, S 173.

210 Briefregister (wie Anm.13) Nr. 56, S. 107.

211 (1414 Dezember 4) Briefregister (wie Anm.13) Nr.99, S. 131.

212 Ebd., Nr.266, S.218f.

213 Voigt (wie Anm. 27), Bd.7, S. 290-293.

214 WeIse (wie Anm. 188) Nr.131, S. 128-133.

215 Ebd., Nr.131, S. 132

216 Ebd. 


\section{Falkengeschenke}

Um seine politischen Interessen zu verfolgen, beließ es der Deutsche Ordens allerdings nicht allein bei schriftlichen Bitten. Er verschenkte auch in großem Maßstab Jagdfalken an fremde Herrschaftsträger, um für seine Politik Werbung zu machen ${ }^{217}$. Denn die Falken des Hochmeisters waren sehr begehrt, weil die Beizjagd ein äußerst beliebter Adelssport war und die Tiere „als besonders gut ausgebildet und abgerichtet galten "218. Dass die Falkengeschenke auch als adliges Abgrenzungsmerkmal dienen konnten, wird ihren Wert bei den Beschenkten noch gesteigert haben ${ }^{219}$.

Mit den im Folgenden erwähnten Falken wird höchstwahrscheinlich der Wanderfalke (Falco peregrinus) gemeint sein ${ }^{220}$. Die meist im Ordensland gefangenen Falken wurden in sogenannten Falkenschulen abgerichtet ${ }^{221}$. Im Oktober eines Jahres brachte man sie zu den Empfängern. Sie wurden in sogenannten Kasen, mit Leinwand bespannten Holzkäfigen, dorthin transportiert ${ }^{222}$. Pro Kase konnten zehn Falken befördert werden. Aus praktischen Gründen wurden gegebenenfalls mit einer Kase die Falken mehrerer Empfänger transportiert ${ }^{223}$. So wie üblicherweise Werbegeschenke mit der Bezeichnung des Schenkers versehen sind, wurden den Falken oft silberne, mit dem Wappen des Hochmeisters versehen Schildchen beigegeben ${ }^{224}$.

Solche Falkengeschenke wurden vom Deutschen Orden längere Zeit als Mittel der Ordenspolitik eingesetzt ${ }^{225}$. Zu den Empfängern der Falken gehörten der römische, englische und französische König sowie deutsche und europäische Fürsten

217 Jürgen SARnowsky, Die Wirtschaftsführung des Deutschen Ordens in Preußen 1382-1454 (Veröffentlichungen aus den Archiven Preußischer Kulturbesitz 34), Köln/Weimar/Wien 1993, S.382; Gustavgeorg Knabe, Preußische Falken im Dienste der Politik des Deutschen Ordens, in: Preußenland 7 (1969) S. 17-21, hier S. 18.

218 Nele Kaestner, Tiere als Mittel der Repräsentation und Diplomatie im Deutschen Orden im Lichte des Marienburger Tresslerbuchs (1399-1409), in: Joachim LAczNy/Jürgen Sarnowsky (Hg.), Perzeption und Rezeption. Wahrnehmung und Deutung im Mittelalter und in der Moderne (Nova Mediaevalia 12), Göttingen 2014, S.67-105, hier S. 77.

219 Hammes (wie Anm. 8) S. 57 Anm. 202.

220 Johannes Voigt, Über Falkenfang und Falkenzucht in Preußen, in: Neue Preußische Provinzialblätter 7 (1849) S.257-276, hier S.258, der die Bezeichnung „Edelfalke“ verwendet.

221 Dies und das Folgende nach Voigt (wie Anm. 220) S.264f.

222 Dies und das Folgende nach Knabe (wie Anm. 217) S. 18.

223 Auch die für Eberhard bestimmten Falken wurden mit denen für andere Empfänger zusammen transportiert: Markgrafen von Meißen, die Jahre 1399-1401, 1405, TB (wie Anm.12) S.37, 77, 124, 362; Herzog von Österreich, das Jahr 1402, ebd., S.194; Burggraf von Nürnberg, die Jahre 1403, 1404, 1407, 1409, ebd., S. 272, 323, 448, 594.

224 Kaestner (wie Anm. 218) S. 87.

225 Knabe (wie Anm. 217) S. 18. 
und Herren ${ }^{226}$. Die Falkengeschenke des Hochmeisters zeichnen sich dadurch aus, dass sie regelmäßig jährlich und systematisch versandt wurden ${ }^{227}$. Es stand also eine durchdachte langfristig angelegte Strategie hinter diesen Geschenken. Die Anzahl und Art der Falken variierte dabei in Abhängigkeit vom formalen aber auch informellen Rang des Beschenkten ${ }^{228}$. So lassen sich an den Falkengeschenken der langfristige und tatsächliche soziale Rang der Beschenkten ablesen.

Neben der Preußenreise Eberhards zogen besonders auch diese Falkensendungen des Deutschen Ordens die Aufmerksamkeit der Historiker auf sich ${ }^{229}$. Im Zeitraum von 1397 bis 1412 erhielt der Graf in zwölf Jahren Falken zum Geschenk $^{230}$. Das erste nachweisbare Falkengeschenk (1397) ist im Ordensbriefarchiv überliefert ${ }^{231}$. Für den Zeitraum von 1399 bis 1409, mit Ausnahme von 1406, finden sich im Tresslerbuch Nachweise für Falkengeschenke ${ }^{232}$. Für 1406 werden im Tresslerbuch als Empfänger solcher Geschenke lediglich Herzog Leopold von Österreich, der römische König - also Ruprecht (1400-1410) - sowie die Kurfürsten erwähnt, die übrigen Beschenkten werden lediglich summarisch mit etc. benannt, also könnte Eberhard darunter gewesen sein. Dann ist noch einmal für 1412 eine Falkensendung an ihn nachweisbar ${ }^{233}$. In der Falkenliste von 1413 ist der Name des württembergischen Grafen dann nicht mehr aufgeführt ${ }^{234}$.

Es lässt sich nachträglich nicht mehr feststellen, ob Eberhard in den Jahren 1398, 1410 und 1411 keinen Falken erhalten hat, oder schlicht und einfach die darüber vorhandene Quellenüberlieferung verloren gegangen ist bzw. noch nicht aufgefunden wurde. Lediglich für 1413 gibt es einen sicheren Nachweis, dass Eberhard im Gegensatz zu anderen Fürsten und Herren keinen Falken erhalten hatte. Es kann daher nur spekuliert werden, in wieweit die aktuelle politische Lage des Ordens oder auch das Verhalten Eberhards sich auf die Falkensendungen auswirkte. Angesichts des hohen symbolischen Werts der Falken erscheint die Nichtberücksichtigung Eberhards als deutlicher diplomatischer Affront ${ }^{235}$.

226 Werner Paravicini, Tiere aus dem Norden, in: Deutsches Archiv für Erforschung des Mittelalters 59 (2003) S. 559-591, hier S. 569.

227 Ebd., S. 567.

228 Dieter Heckmann, Preußische Jagdfalken als Gradmesser für Außenwirkung europäischer Höfe des 15. und 16. Jahrhunderts, in: Preußenland 37 (1999) S.39-62, hier S. 41.

229 Sснӧ 1903 (wie Anm. 11) S. 85 f.; Hammes (wie Anm. 8) S.78.

230 (1397) GStA PK XX HA, OBA Nr. 555; (1399-1409) Kaestner (wie Anm. 218) S. 98; (1412) GStA PK XX HA OF 6, p. 5.

231 GStA PK XX HA, OBA Nr. 555.

232 TB (wie Anm. 12) S. 37, 77, 124, 194, 272, 323, 362, 448, 506, 594. Die Jahre 1407 und 1408 sind auch in den Falkenlisten nachweisbar, GStA PK XX HA, OF 3, p. 8, 11.

233 GStA PK XX HA, OF 6, p. 5.

234 Ebd.

235 Pfalzgraf Ludwig III. (1410-1436) reagierte 1420 sehr heftig, als die Anzahl der Falken geringer als gewohnt war und drohte mit handelspolitischen Restriktionen; vgl. KNABE (wie Anm.217) S. 20 mit weiteren Beispielen von enttäuschten Empfängern. 
Die Größe des Falkengeschenks an Eberhard ist für 1397, 1404, 1407, 1408 und 1412 nachweisbar; es handelte sich jeweils um vier Falken pro Jahr ${ }^{236}$. Als Beispiel für die unterschiedliche Größe der Falkengeschenke an verschiedene Empfänger sei hier das Jahr 1408 aufgeführt. Damals bekam beispielsweise König Ruprecht zwölf, der Erzbischof von Köln sechs und Graf Eberhard vier Falken ${ }^{237}$. Damit stand der württembergische Graf auf einer Stufe mit dem Burggrafen von Nürnberg, dem Herzog von Sachsen, den beiden Markgrafen von Meißen, dem Grafen von Katzenelnbogen und dem Herzog von Geldern, die ebenfalls jeweils vier Falken erhielten ${ }^{238}$. Das bedeutete für Eberhard, einem Grafen ohne Fürstenrang, eine enorme Wertschätzung, die seiner Dynastie und Herrschaft zugute kam.

\section{Herolde}

Um die württembergisch-preußischen Beziehungen aufrechtzuerhalten, wurden Gesandte und Boten benötigt, welche die Nachrichten austauschten. Im vorliegenden Fall übernahmen Herolde diese Funktion. Im Tresslerbuch werden in den Jahren 1401 bis 1408 württembergische Herolde erwähnt, denen ein Botenlohn ausgezahlt wurde ${ }^{239}$. So findet sich dort beispielsweise folgender Eintrag: item $2 m$ [ark] des groffen herbolde von Wirtenberg gegeben am montage noch Judica [13. März 1402] ${ }^{240}$. Die Herolde wurden nach ihrem Herren benannt ${ }^{241}$. So heißt es im Tresslerbuch für das Jahr 1408: item $10 \mathrm{~m}$ [ark] Wirtenberge dem herolde gegeben $^{242}$. Im Tresslerbuch werden zwar häufig Boten genannt, jedoch keine des Grafen von Württemberg ${ }^{243}$.

Die nachweisbaren Aufenthalte von württembergischen Herolden standen nicht im Zusammenhang mit den Falkentransporten, denn die Daten der im Tresslerbuch genannten Falkenversendungen nach Württemberg und die Aufenthalte

236 (1397) GStA PK XX HA, OBA Nr. 555; (1404) GStA PK XX HA, OF 3, p. 8; (1407) GStA PK XX HA, OF 3, p. 8; (1408) GStA PK XX HA, OF 3, p. 11 u. Paravicini (wie Anm. 226) S.567; (1412) GStA PK XX HA OF 6, p. 5.

237 Florian (wie Anm. 1) S. 89.

238 Ebd.

239 TB (wie Anm. 12) S. 114 u. 126 (Jahr 1401) S. 156 u. 192 (Jahr 1402), S. 252 (Jahr 1403), S. 300 (Jahr 1404), S. 356 u. 361 (Jahr 1405), S. 383 (Jahr 1406), S. 440 (Jahr 1407), S. 462 u. 477 (Jahr 1408); Schön (wie Anm.11) S.86f., 153; Nils Bock, Die Herolde im römisch-deutschen Reich. Studien zur adligen Kommunikation im späten Mittelalter (Mittelalter-Forschungen 49), Ostfildern 2015, S. 141 Anm. 437.

240 TB (wie Anm. 12) S. 156.

241 Bock (wie Anm. 239) S. 142.

242 TB (wie Anm. 12) S. 477; SснӧN 1903 (wie Anm. 11) S. 153.

243 Im Tresslerbuch werden an 231 Stellen Botschaften genannt, die an den Hochmeister gingen oder von diesem versandt wurden, TB (wie Anm. 12) S. 659. 
der Herolde fielen mit einer möglichen Ausnahme zeitlich nicht zusammen ${ }^{244}$. Die erwähnten Herolde werden andere diplomatische Aufgaben gehabt haben. Herolde wurden damals häufig im diplomatischen Dienst als Überbringer schriftlicher oder auch mündlicher Botschaften eingesetzt ${ }^{245}$, so wie jener im Tresslerbuch erwähnte Herold, der 1402 einen Brief des Markgrafen von Meißen an den Hochmeister überbrachte ${ }^{246}$.

Wertet man die Vorkommen der Herolde im Tresslerbuch aus, dann kommt man zu einem erstaunlichen Ergebnis. Von den 61 verschiedenen Herrschern, Fürsten und Adligen zuordenbaren Heroldsnennungen lassen sich zwölf auf Württemberg beziehen. Dies ist der höchste Wert! Die nächst größere Gruppe von sieben Herolden lässt sich Vytautas zuordnen. Es lässt sich auch eine Regelmäßigkeit bei den Belegen für württembergische Herolde erkennen: Zwischen 1401 und 1408 sind für jedes Jahr ein bzw. für 1405 und 1407 zwei Herolde nachzuweisen. Das deutet für diesen Zeitraum auf einen regelmäßigen diplomatischen Kontakt zwischen dem Orden und Württemberg hin ${ }^{247}$. Es ist dabei auch zu bedenken, dass im Tresslerbuch möglicherweise nicht alle finanziellen Ausgaben über württembergische Herolde verzeichnet wurden ${ }^{248}$.

Für 1411 gibt es dann einen weiteren Nachweis eines württembergischen Herolds, der im Ordensland geweilt hatte. In einem Schreiben des Straßburger Ammanmeisters Johann Heilmann an den Speyerer Altbürgermeister Conrad Roesler berichtet dieser nämlich von neuen Nachrichten (nuwe mere), welche Herolde des Markgrafen von Baden und des Grafen von Württemberg, die am 1. März von ihrer Rückreise aus Preußen in Stuttgart eingetroffen waren, mitgebracht hatten ${ }^{249}$. Hier wird dann eine weitere wichtige Aufgabe des Herolds neben dem Überbringen diplomatischer Botschaften deutlich, nämlich die Beschaffung möglichst aktueller Informationen ${ }^{250}$.

Es ist davon auszugehen, dass 1399 bis 1409 nicht nur Herolde Briefe überbrachten, doch dafür findet sich im Tresslerbuch kein Nachweis. Briefe, die mit Sammelsendungen befördert wurden, sind im Tresslerbuch ebenfalls nicht nachweisbar. Es wird häufiger solche Kontakte gegeben haben, als diese überliefert sind. Wie die oben schon erörterten Briefe des Hochmeisters zeigen, wurde auch nach 1409 der

244 Auch die Erwähnung eines Herolds für den 3. November 1402 steht wohl nicht damit in Zusammenhang, denn die Falkenkase wurde erst am 29. November abtransportiert, s. TB (wie Anm.12) S.192, 194.

245 Dazu Bock (wie Anm. 239) Kap. C. 6.1.

246 TB (wie Anm.12) S. 168. Die Leitung von Verhandlungen hatten sie allerdings nicht, Bock (wie Anm.239) S. 235.

247 Vgl. Hammes (wie Anm. 8) S. 78.

248 Es wurden nicht alle angefallenen Rechnungen verzeichnet, dazu Vorwort in TB (wie Anm.12) S. IV f.

249 (1411 März 8) RMB 1, Nr. 2663, S. 275 f.

250 Vgl. Bock (wie Anm. 239) S. 222 Anm. 669. 
Briefaustausch - ob mit Herolden, Boten oder durch Sammelsendungen - weitergepflegt.

\section{Gründe für die Beziehungen Eberhards zum Deutschen Orden}

Die Gründe des Deutschen Ordens für die Anbahnung von Beziehungen zu Graf Eberhard wurden schon oben ausgeführt. Darunter war vor allem die Suche nach politischer Unterstützung in der Auseinandersetzung mit Polen-Litauen von Bedeutung. Welche Gründe hatte aber Eberhard, um sich auf eine Preußenreise zu begeben und lange anhaltende Beziehungen zum Orden aufzubauen? Sie sind in den Quellen nicht überliefert. Doch wird in der Forschung schon längere Zeit über die allgemeine Motivation von Adligen zu den Preußenreisen diskutiert. Die Ergebnisse lassen sich auch auf die Person Eberhards übertragen.

Die Litauerreisen waren beim europäischen Adel deshalb so beliebt, weil sie es den Teilnehmern ermöglichten, dem Ideal des miles christianus nachzueifern ${ }^{251}$. Dieses in der beginnenden Kreuzzugszeit definierte Idealbild verband das Streben nach Seelenheil mit dem Streben nach Kampfesruhm. So konnte der adlige Streiter durch den Kampf gegen die Ungläubigen für die Verteidigung des Christentums sein Seelenheil erlangen. Denn Litauerreisen wurden als Kreuzzüge betrachtet ${ }^{252}$, bei denen es für die Teilnehmer einen Sündenablass gab ${ }^{253}$. Werner Paravicini erfasst dieses Spannungsfeld mit den Begriffen devotio, also Opferbereitschaft für den Glauben, und militia, also Bestreben nach (weltlicher) ritterschaftlicher Betätigung ${ }^{254}$. Das oben genannte Schreiben des Hochmeisters Heinrich von Jungingen vom Mai 1410 etwa zielte auch auf solche Glaubensüberzeugungen, indem es die Fürsten und Herren aufforderte czu beschirmunge der beiligen cristenbeit ${ }^{255}$.

Der Deutsche Orden war als aristokratisch orientierter Ritterorden besonders als Gastgeber des europäischen Adels geeignet ${ }^{256}$. Auf geschickte Weise ging er auf die Bedürfnisse seiner adligen Gäste vor allem nach weltlich-ritterlichen Erlebnissen ein ${ }^{257}$. Es wurde für die Gäste eine ritterliche Idealwelt inszeniert, wie z.B.

251 Dies und das Folgende nach J. Fleckenstein, Ritter, -tum -stand I, in: LexMa 7, Sp. 865-873, hier Sp. 869.

252 Paravicini (wie Anm. 43) S.29. Es gab im Spätmittelalter auch weitere „Fronten des Heidenkampfes“ auf der Iberischen Halbinsel, im östlichen Mittelmeerraum sowie auf dem Balkan, vgl. Detlev Kraack, Pilgerfahrten und Reisen von West nach Ost und von Ost nach West. Beziehungsgeschichtliche Perspektiven adliger Mobilität im Spätmittelalter, in: Der Jakobuskult in Ostmitteleuropa. Austausch, Einflüsse, Wirkungen, hg. von Klaus HerBers/Dieter R. Bauer (Jakobus-Studien 12), Tübingen 2003, S. 57-74, hier S. 66.

253 Paravicini (wie Anm. 43) S. 29.

254 Ebd., S. $28 \mathrm{ff}$.

255 CEV (wie Anm. 173) Nr. 440, S. 207.

256 Vgl. Paravicini (wie Anm. 43) S. 33.

257 Dazu Brinker (wie Anm. 33) S. 108. 
durch die Ausrichtung des oben erwähnten Ehrentisches ${ }^{258}$, der zunächst nicht der Selbstdarstellung der Fürsten und hohen Adligen, sondern jener der ritterlich-niederadligen Kämpfer diente ${ }^{259}$. Rittererhebungen waren ein wichtiger Bestandteil davon $^{260}$. Auch das bei der Litauerreise 1393 nachweisbare Recht des Bannertragens, das an Niederadlige vergeben wurde, war ein solches Element ${ }^{261}$.

Die Kombination von Einsatz für den Glauben, Streiten für den weltlichen Ruhm und das ritterliche Ambiente verbunden mit der gediegenen „Empfangsstruktur“262 machten beim Adel die Beliebtheit der Preußenreisen aus. Die Attraktivität der Preußenreisen beim Adel wurde noch dadurch gesteigert, dass es sich dabei um exklusiv adlige Veranstaltungen handelte ${ }^{263}$. Schließlich mussten die Teilnehmer in Hinblick auf ihren Lebensstil auch keine allzu großen Abstriche machen ${ }^{264}$. Zusätzlich hatten die Preußenfahrten für die Teilnehmer eine bedeutende repräsentative Funktion. Eine Preußenreise befriedigte nicht nur individuelle innere religiöse Bedürfnisse oder das Streben nach Abenteuern, sondern vermehrte auch das Prestige der ganzen Dynastie ${ }^{265}$.

Für die Verbreitung des Ruhms sorgten dann die Teilnehmer selbst. Zur Selbstrepräsentation gehörte natürlich auch das Auftreten mit einem großen Gefolge, das Rückschlüsse auf das Ansehen der Person zuließ. In Quellen zu den Preußenreisen wird deswegen immer wieder die Größe des Gefolges genannt ${ }^{266}$. Demnach soll Eberhard mit 200 Reitern in Preußen gewesen sein ${ }^{267}$. Nimmt man die Gefolgschaftsgröße als Maßstab für das Ansehen, dann war Eberhard damit unterhalb der Könige und großen Landesfürsten und zugleich oberhalb der kleinen Grafen und Herren anzusiedeln ${ }^{268}$. Er gehörte einer mittleren Gruppe an, zu der Hochadlige wie Ufford, Bourbon, Lancaster, Lothringen oder Derby zählten. Für einen Grafen, der nicht dem fürstlichen Stand angehörte, hatte er damit schon ein beachtliches Gefolge, wenn man bedenkt, dass dies genauso groß war, wie jenes des

258 Vgl. Paravicini (wie Anm. 43) S. $31 \mathrm{f}$.

259 Paravicini (wie Anm. 23), Bd.1, S. 324.

260 Ebd., Bd.2, S. 130.

261 Dazu ebd., S. 140.

262 Paravicini (wie Anm. 43) S. 32.

263 Ebd., S. 33.

264 Bujack (wie Anm. 84) S.676; vgl. Militzer (wie Anm. 53) S. 176.

265 Zur Betonung des „feudal-höfischen Repräsentationscharakters“ bei Suchenwirt, s. Bernd MüLler, ,Ich han gewandelt manig her/gen Preussen, Reussen, uber mer`. Zur Problematik der Preußenfahrten bei Oswald von Wolkenstein, in: Jahrbuch der Oswald von Wolkenstein Gesellschaft 5 (1988/89) S. 465-477, hier S. 472.

266 Vgl. dazu Bujack (wie Anm. 84) S. 676f.; Paravicini (wie Anm. 23), Bd. 1, S. 177-181. 267 Franciscani Thorunensis Annales Prussici (wie Anm.19) S.188. Vergleich der Gefolgschaftsgröße der Preußenfahrer bei Paravicini (wie Anm. 23), Bd.1, S.178-180.

268 Dies und das Folgende nach ebd., S. 181. 
genannten - dem Fürstenstand angehörenden ${ }^{269}$ - Herzogs von Lothringen ${ }^{270}$. Bei der Gefolgschaftsgröße war ein Adliger nicht frei, sondern musste sich dabei an den gesellschaftlichen Gegebenheiten orientieren ${ }^{271}$. Andere nichtschriftliche Zeugnisse herrschaftlicher Repräsentation Eberhards sind, wie schon zuvor erwähnt, nicht überliefert.

Einen weiteren Prestigezuwachs brachten die Falkengeschenke des Deutsche Ordens. Sie waren das Ergebnis einer langfristigen Pflege der bilateralen Beziehungen. Sie vermehrten das Prestige der Beschenkten und bewirkten durch ihre begrenzte Anzahl bei den Beschenkten Exklusivität. Sie werden für Eberhard ein Ansporn gewesen sein, die Beziehungen zu pflegen.

Die Beziehungen Eberhards zum Deutschen Orden passen in das bekannte Bild, das seine repräsentative Selbstdarstellung angesichts seines sozialen Ranges auf einem hohen Niveau zeichnet ${ }^{272}$. Die materielle Grundlage lag in seiner recht bedeutenden Territorialherrschaft in einem für die Reichspolitik wichtigen Gebiet. Darauf baute eine dann als weitere Basis sein weit umfassendes Netzwerk von Bündnissen auf.

Der Hang Eberhards zu einer außerordentlichen Selbstdarstellung kann zunächst herkömmlich erklärt werden, denn für die zeitgenössische Adelsgesellschaft galt der Grundsatz dass „Aufwendige Repräsentation [...] Bestandteil der [sozialen] Existenz" war ${ }^{273}$. Für die Adligen gab es auf dem Gebiet des sozialen Ansehens einen regelrechten Konkurrenzkampf ${ }^{274}$. Eberhard musste sich, um sein Sozialprestige als Graf zu wahren, standesgemäß verhalten.

Doch kann der repräsentativen Selbstdarstellung Eberhards noch eine stärker zielgerichtete Absicht unterstellt werden. Bekanntlich strebten damals erfolgreiche Hochadelsgeschlechter danach, in den Fürstenstand aufzusteigen ${ }^{275}$. Der Fürstenstand sicherte dauerhaft das bestehende Ansehen einer Hochadelsfamilie, verschaffte $^{276} \mathrm{ihr}$ weitere prestigereiche Privilegien wie das Recht auf exklusive Prädikate oder zeremonielle Ehrenvorrechte, und zugleich konnte die Einheit des Herrschaftsgebiets durch eine mit der Fürstenerhebung einhergehenden Umwandlung der Herrschaft in ein Reichslehen dauerhaft gesichert ${ }^{277}$ werden.

269 Peter MoRaw, Von offener Verfassung zu gestalteter Verdichtung. Das Reich im späten Mittelalter 1250 bis 1490, Frankfurt am Main/Berlin 1989, S. 70.

270 Paravicini (wie Anm.23), Bd.1, S. 180.

271 Florian (wie Anm.1) S. 88.

272 Ebd., S. $87 \mathrm{ff}$.

${ }^{273}$ Moraw (wie Anm. 269) S. 69.

274 Dazu Paravicini (wie Anm. 42) S. 36.

275 Ernst Schubert, Fürstliche Herrschaft und Territorium im späten Mittelalter (Enzyklopädie Deutscher Geschichte 35), München 1996, S.10.

276 Karl-Friedrich KrIEger, König, Reich und Reichsreform im Spätmittelalter (Enzyklopädie deutscher Geschichte 14), München 1992, S. 38.

277 Mertens (wie Anm. 1) S. 66. 
Das Haus Württemberg gehörte zu einer Gruppe mächtiger Hochadelsgeschlechter, die vor dem Aufstieg in den Fürstenstand standen oder ihn schon erreicht hatten ${ }^{278}$. Graf Eberhard wurde dabei wie anderen Protagonisten des Hochadels aufgrund seiner Macht und seines hohen Ansehens der Fürstentitel gewissermaßen schon vor einer möglichen Erhebung in den Fürstenstand zuerkannt. Denn im Tresslerbuch wird er 1403 als herzoge von Wirtenberg bezeichnet ${ }^{279}$. Für das Jahr 1404 findet sich ein fast gleichlautender Eintrag ${ }^{280}$. Ob diese Titulierung Absicht war, kann nicht mehr ermittelt werden. Doch selbst wenn es sich bei der Titulierung um ein Versehen handelte, weist sie doch auf das hohe soziale Ansehen Eberhards hin. Graf Eberhard war nicht der Einzige, dem dies widerfuhr, auch Graf Adolf II. von Kleve (1394-1417/48) wurde 1405 im Tresslerbuch als Herzog tituliert ${ }^{281}$ und 1417 dann tatsächlich auch in den Fürstenstand erhoben. Der Brief der Cousins Heinrichs von Plauen aus dem Jahr 1413, in dem Eberhard als Fürst tituliert wird, ist gleichfalls unter diesem Aspekt zu betrachten. Die Tatsache, dass die beiden Cousins von Hochmeister Heinrich von Plauen sich veranlasst sahen, Eberhard als Vermittler einzusetzen, zeugt dabei ebenso von dessen hohem Ansehen, das darüber hinaus offenbar bis Mitteldeutschland ausstrahlte.

Eberhard war möglicherweise schon recht weit auf dem Weg zur Fürstenerhebung. Das Ansehen Eberhards war am Ende seiner Regierungszeit offenbar so hoch, dass es wohl schon damals Gerüchte gab, dass er vom König in den Fürstenstand erhoben werden würde ${ }^{282}$. Es sind auch jenseits der überlieferten Gerüchte Anzeichen vorhanden, dass Eberhard dem Ziel einer dauerhaften Rangerhöhung seines Hauses schon recht nahe war. In einem Brief an den Erzbischof Johann V. von Riga (1393-1418) bezeichnete König Sigmund nämlich den gleichnamigen Sohn Eberhards als illustris Eberhardi comitis de Virtenberg iunioris ${ }^{283}$. Das Prädikat illustris war jedoch nur weltlichen Reichsfürsten vorbehalten, selbst die in der Rangskala niedriger stehenden Fürstengenossen, die nur für ihre Person - nicht für ihr Land - den Fürstenrang innehatten, durften ein solches Prädikat nicht verwenden ${ }^{284}$. Bevor es jedoch zu einer möglichen Erhebung des württembergischen Grafen in den Fürstenrang kommen konnte, vereitelten offenbar politische Unstimmigkeiten mit König Sigmund bzw. Eberhards Tod im Jahr 1417 das Vorhaben ${ }^{285}$.

\footnotetext{
278 Krieger (wie Anm. 276) S. 38.

279 TB (wie Anm. 12) S. 252.

280 Ebd., S. 300.

281 Heckmann (wie Anm. 228) S. 41.

282 Florian (wie Anm.1) S. 91.

283 Ebd., S. 90 Anm. 122.
}

284 Karl-Friedrich KrIEger, Fürstliche Standesvorrechte im Spätmittelalter, in: Blätter für deutsche Landesgeschichte 122 (1986) S.91-116, hier S. 96 ff. - Eine Ausnahme wurde lediglich bei den Burggrafen von Nürnberg seit dem Ende des 14. Jahrhunderts gemacht, ebd., S. 97.

${ }^{285}$ Florian (wie Anm. 1) S. 91. 
Das Geschilderte hat die Überlegung zur Folge, ob nicht die für einen Grafen auffallend aufwändig betriebene Repräsentation Teil einer Strategie Eberhards III. war, den Fürstenstatus zu erlangen ${ }^{286}$. Neben einer ausreichenden Herrschaftsbasis bzw. lehnsrechtlichen Voraussetzungen war natürlich auch das Ansehen der Dynastie ein Kriterium der Fürstenerhebung bzw. Voraussetzung für die Akzeptanz des neuen Titels. Die neuen Standesgenossen waren ebenso daran interessiert, dass ihr „Zuwachs“ eine den bisherigen Stand übersteigende Vornehmheit ja Ebenbürtigkeit (mit dem neuen Stand) aufweisen konnte ${ }^{287}$. Als etwa bei der Erhebung Eberhards V. (1459-1496) zum Herzog bzw. in den Fürstenstand 1495 der kaiserliche Rat Veit von Wolkenstein eine die Zeremonie einleitende Empfehlungsrede auf den neuen Herzog hielt, unterstrich er u.a. das herbringen fürstlich stands, der in dem hus Wirtemberg allweg loblich herbracht und gebalten sy ${ }^{288}$. Eine Urkunde über diese Herzogerhebung besagt dann auch, dass das Haus Württemberg Vorfahren von fürstenmäßiger Abstammung und ebensolchem Auftreten aufzuweisen habe ${ }^{289}$. Wenn Eberhard III. also den Fürstenrang anstrebte, dann war es für ihn angebracht, schon vor einer möglichen Fürstenerhebung seiner repräsentativen Selbstdarstellung ein fürstliches Niveau zu geben.

Die Preußenreise, die Teilnahme an einer „erfolgreichen“ Litauerreise und die Falkengeschenke wiederum waren ein wertvoller Beitrag zur dafür erforderlichen Steigerung von Eberhards Ansehen. Weil die Falkengeschenke das Prestige des Beschenkten steigerten und zugleich ein Gradmesser dafür sind, soll nochmals ein Blick auf die Verteilung der Falkengeschenke im Jahr 1408 geworfen werden. Denn mit seinen vier Falken war er dem Herzog von Sachsen, der den Kurfürstenrang innehatte, ${ }^{290}$ sowie den Burggrafen von Nürnberg, welche Fürstengenossen ${ }^{291}$ waren, gleichgestellt. Der württembergische Graf erhielt bemerkenswerterweise auch die gleiche Anzahl an Falken wie die Erzbischöfe von Mainz und Trier, welche ebenfalls Kurfürsten waren ${ }^{292}$. Schließlich bekam er sogar doppelt so viele Falken wie der Graf von Henneberg, welcher immerhin gleichfalls Fürstengenosse ${ }^{293}$ $\operatorname{war}^{294}$.

286 Zur fürstlichen Repräsentation Schubert (wie Anm. 275) S.36f.

287 Dieter Mertens, Der Fürst. Mittelalterliche Wirklichkeiten und Ideen, in: Der Fürst. Ideen und Wirklichkeiten in der europäischen Geschichte, hg. von Wolfgang Weber, Köln u. a. 1998, S.67-89, hier S. 83.

288 Mertens (wie Anm.287) S. 83.

289 Ebd., S. 83.

290 Moraw (wie Anm. 269) S. 70.

291 Krieger (wie Anm. 276) S. 39.

292 GStA PK XX HA, OF 3, p. 11; s. auch Paravicini (wie Anm. 226) S. 569.

293 Krieger (wie Anm. 276) S. 39.

294 GStA PK XX HA, OF 3, p. 11. - Falsch, mit jeweils vier Falken für die beiden Markgrafen von Meissen, Paravicini (wie Anm. 226) S. 569. 


\section{Ergebnis}

Die Untersuchung hat gezeigt, dass die Beziehungen zwischen Württemberg und dem Deutschen Orden in der Regierungszeit Eberhards III. keinen Randaspekt der südwestdeutschen Landesgeschichte darstellen. Vielmehr sind die Beziehungen, vor allem nachweisbar für die Zeit des Tresslerbuchs (1399-1409), durch Regelmäßigkeit gekennzeichnet. Beide Seiten hatten Interesse an der Aufrechterhaltung und Pflege der beiderseitigen Beziehungen. Die Motive des Deutschen Ordens liegen auf der Hand, er benötigte politische und militärische Unterstützung in seinem Kampf gegen Polen-Litauen. Für Graf Eberhard lag der Nutzen in der Mehrung des Ansehens seiner Person und seines Hauses durch die Teilnahme an der Preußenfahrt und den Erhalt preußischer Jagdfalken. Die Mehrung des Ansehens der eigenen Familie war ein wichtiges Ziel seiner herrschaftlichen Politik. So lassen sich die Entscheidung Eberhards zu einer Preußenreise und seine Pflege der Beziehungen zum Orden - von weiteren individuellen Motiven abgesehen auch als Ausprägungen eines besonderen politischen Stils interpretieren, in dessen Rahmen der württembergische Graf den erstrebten Aufstieg seines Hauses in den Fürstenstand aktiv durch Steigerung seines Prestiges zu befördern suchte. 